\title{
Monetary Policy and Treasury Risk Premia
}

\author{
Andrea Buraschi, Andrea Carnelli, and Paul Whelan \\ A.BURASCHI@IMPERIAL.AC.UK \\ ANDREA.CARNELLI08@IMPERIAL.AC.UK \\ PAUL.WHELAN07@IMPERIAL.AC.UK
}

\begin{abstract}
This paper investigates the role of monetary policy as a source of time-varying priced risk in bond markets. We use individual agents forecasts of Federal Funds, GDP and inflation to construct an empirical proxy for policy shocks from the residuals of Taylor rule regressions. Key to our analysis is a distinction between (pro-cyclical) target rate shocks and (counter-cyclical) path shocks. We show that path shocks account for between $10 \%-15 \%$ of the variance of one-year expected excess returns on bonds with maturities $2-5$ years and are also priced in the cross-section of equity returns.
\end{abstract}

JEL classification: G12, E43, E52

Keywords: Fixed Income, Return Predictability, Monetary Policy, Taylor Rules.

First version: December, 2012.

This version: March, 2014.

Andrea Buraschi, Andrea Carnelli, and Paul Whelan are at Imperial College London Business School. We would like to thank Marcin Kacperczyk, Alessandro Beber, Stanley Zin, Pietro Veronesi and conference participants at San Diego AFA Meetings 2013, Zurich SGF Conference 2013, Reading EFMA Meetings 2013 for useful comments and suggestions. The usual disclaimer applies. 


\section{Introduction}

Monetary policy and bond prices are connected via two channels. Firstly, central banks use the nominal short-term rate as a primary policy instrument. Secondly, the absence of arbitrage opportunities implies that bond yields reflect risk neutral expectations about future short rates. Hence, both institutional features (short rate as a policy instrument) and economic restrictions (no arbitrage) enforce a fundamental link between monetary policy and entire term structure of interest rates. Indeed, a large literature documents strong responses in yields to news about monetary policy (see, for instance, Kuttner (2001), Fleming and Piazzesi (2005), and Gurkaynak, Sack, and Swanson (2005)). However, little is known about whether there is a link between montary policy and bond risk premia. This paper uses a new approach to identify expectations about the future path of monetary policy and shows that path shocks represent a source of priced risk and are important in explaining time-variation in bond risk premia.

Empirically, measuring the actions of monetary policy is a challenging task. A first difficulty is related to the fact that a significant component of policy actions reflects the systematic response of the policy instrument to the macro-economic environment, rather than exogenous policy shocks. In practice, researchers make identifying assumptions to be able to disentangle the systematic component from the monetary policy shock. Needless to say, the dynamic properties of the resulting decomposition are highly dependent on these assumptions (Christiano, Eichenbaum, and Evans (1999)). A second difficulty is that data on short-term target changes is unlikely to capture the richness of policy decisions. For instance, market participants may fully foresee target rate changes, but be considerably surprised about the path of future policy as inferred from the statements of the members of the policy committee: in these circumstances, a measure of monetary policy shocks based on the policy instrument alone may significantly under-estimate the extent of exogenous variation in monetary policy. This concern is particularly important for our setting, since monetary policy is known to influence long term yields more via path than target surprises (Gurkaynak, Sack, and Swanson (2005)). This possibility is widely understood by policymakers:

The current funds rate imperfectly measures policy stimulus because the most important economic decisions, such as a family's decision to buy a new home or a firm's decision to acquire new capital goods, depend much more on longer-term interest rates, such as mortgage rates and corporate bond rates, than on the federal funds rate. Long-term rates, in turn, depend primarily not on the current funds rate but on how financial market participants expect the funds rate and other short-term rates to evolve over time.' (Bernanke (2004b)).

In this article, we propose a novel approach to measuring path shocks which addresses both challenges. The key results of the paper are summarised as follows.

First, we construct an empirical proxy for path shocks from the residuals of a Taylor rule estimated on survey expectations. Central to this analysis is a new data set that includes joint 
expectations about the target rate (fed fund rate) and economic fundamentals (GDP and inflation). This data set is compiled at monthly frequency and is available in a panel data form so that, for each individual, we have observations on the expected counterparts to both the left and right-hand side of the Taylor rule. Importantly, this dataset allows us to empirically identify a measure of path shocks without making assumptions about the data generating process in the mind of agents. While real-time and truly forward-looking, the use of survey forecasts may introduce additional concerns. In order to ensure that the survey biases are quantitatively negligible we conduct a host of quality checks. When we compare the properties of subjective macro expectations to those obtained from traditional econometric benchmarks, we find that the errors of consensus forecasts are in absolute value lower than their econometric counterparts. This is especially true for the Fed fund rates forecasts. This result is interesting and highlights the potential importance of structural breaks in the conduct of policy decisions. Another advantage of the panel structure of the data is that it circumvents the need to use pre-aggregated consensus data, which may in itself bias the results. Indeed, we compare models based on pre-aggregated consensus data, or panel data, using (i) pooled OLS, (ii) fixed effects, (iii) random effects, and find that a panel data approach is preferable to procedures based on pre-aggregated consensus data.

Second, to understand the relative importance of target versus path shocks we consider three alternative measures proposed by the literature: (i) the residuals from an orthogonalised monthly VAR (Christiano, Eichenbaum, and Evans (1996)); (ii) the daily change to the 1-month Federal funds futures rates around FOMC announcements (Bernanke and Kuttner (2005)); and (iii) the daily change in the 6-month euro-dollar rate around FOMC announcements (Cochrane and Piazzesi (2002)). An intriguing yet robust finding is that target shocks are negatively correlated to path shocks. This is interesting since we learn that short-term policy actions are linked to the formation of expectations about future policy actions. Moreover, path shocks are on average countercyclical, different than target shocks, which are procyclical. This observation is consistent with a term structure of interest rates in which the short end is pro-cylical driven primarily by target shocks and the long end is counter-cyclical driven primarily driven by risk compensation.

Third, we find that monetary policy path shocks represent an empirically important source of priced risk in bond markets. This contrasts with the role played by (high-frequency) target shocks. In a predictability regression of bond excess returns onto lagged path shocks we find that a one standard deviation increase in the right hand side predicts an increase in future excess returns by $\sim 0.40$ standard deviations. The statistical significance is also large: the null of no predictability is always rejected at the $1 \%$ level and path shocks alone account for $15 \%$ of the variance of bond excess returns. We show that the evidence: (i) is robust across a variety of Taylor rule specifications; (ii) is present both in the full sample and in a subsample that excludes the last financial crisis; and (iii) survives after controlling for the contemporaneous level of macroeconomic activity.

Fourth, our proxy of monetary policy path shocks features strong co-movement with the risk 
premium factors based on yield curve information proposed by Cochrane and Piazzesi (2005) and Le and Singleton (2013). Univariate regressions of monetary policy path shocks onto the factor of Cochrane and Piazzesi (2005) or Le and Singleton (2013) yield $R^{2}$ of up to $12 \%$ and $23 \%$, respectively. In order to confirm the robustness of these results we construct a factor mimicking portfolio in the space of equities and quantify the extent to which monetary policy path shocks help explain the cross section of equity returns, after controlling for the Fama and French factors. Indeed, we find that the price of monetary policy path risk estimated in the second stage regressions is $4.40 \%$ on an annualized basis, an economic magnitude that is second only to the market risk premium. This result highlights that monetary policy path shocks have pervasive effects in both bond and equity markets.

Finally, we explore theoretical explanations for how monetary policy may affect the dynamics of risk premia, which we study in the context of economies with either time-varing prices of risk or with time-varying quantities of risk. In the context of a habit economy (time-varying price of risk), monetary policy may be important due to the effect of money non-neutrality on the dynamics of consumption surplus. ${ }^{1}$ In these economies, the marginal utility of agents depends on the distance of consumption from habit: agents become relatively more risk averse when consumption drops relative to its recent trend. Hence, if monetary policy affects consumption (if money is non-neutral), it also affects marginal utility and the level of risk aversion of investors. To the extent that contractionary policies have a negative impact on consumption, a (positive) monetary policy shock will increase the price of risk as consumption falls closer to the habit stock. ${ }^{2}$ The link between monetary policy and risk premia can be also understood in the context of long run risk economies (time-varying quantities of risk) (see, for instance, Bansal and Yaron (2004) and Bansal and Shaliastovich (2013)). Since predictability is an implication of heteroskedastic fundamentals in long run risk economies, if monetary policy affect the conditional volatility of GDP growth and inflation, it may generate time varying risk premia in bond returns. Given the large debate about the significance of monetary policy as a major determinant of economic (in)stability (see, for instance, Bernanke (2004a)), the long run risk perspective is, next to habit models, an insightful channel to understand the potential link between monetary policy and risk premia. In order to study these channels, we assess the forecasting ability of path shocks for a proxy of consumption surplus and the conditional volatilities of inflation and real economic growth. Using a range of tests we find the link with consumption surplus is weak, but that projections of real economic uncertainty onto path shocks yields an $R^{2}$ equal to $\sim 20 \%$. Thus, the previous results are consistent with a long run risk interpretation (quantity of risk channel), and suggest that monetary policy shocks make their way into risk premia by affecting the overall level of macroeconomic uncertainty.

\footnotetext{
${ }^{1}$ Money non-neutrality indicates the idea that monetary policy influences not only nominal quantities such as inflation and exchange rates, but also real aggregates such as employment, GDP, and consumption (see King (2000) and Christiano, Eichenbaum, and Evans (1999), for a review).

${ }^{2}$ The theoretical literature has studied this channel either in the context of internal habit formation, as in Sundaresan (1989), Constantinides (1990), and Heaton (1995), or in external habit specifications, as in Campbell and Cochrane (1999), Wachter (2006), and Buraschi and Jiltsov (2007)
} 
The rest of the paper is organized as follows. After a discussion on how this work relates to the existing literature, Section II describes the data. Section III reviews the details behind the construction of monetary policy shocks, while Section IV presents the core evidence on bond return predictability. Next, section $\mathrm{V}$ investigates whether the evidence is consistent with a price of risk, or quantity of risk channel. Section VI concludes.

\section{A. Related literature}

This paper is related to two streams of the literature. A first stream studies the implications of monetary policy announcements on realized returns and volatility of asset prices. Some of these empirical studies use the FOMC Federal Open Market Committee) meetings to identify releases of information about the conduct of monetary policy. The use of announcements is interesting because it allows to identify shocks to the information set of agents and understand the transmission mechanism of monetary policy. A classic study is Kuttner (2001), who disentangles the expected and unexpected components of monetary policy from federal funds futures and finds that the latter accounts for a large fraction of the daily variation of bond yields around FOMC announcements. He also finds, however, that the fraction of variance that can be accounted for by monetary policy surprises declines in maturity. Thus, it is not clear to what extent the fluctuations observed during the release of FOMC announcement can be entirely attributed to policy news. Fleming and Piazzesi (2005) and Gurkaynak, Sack, and Swanson (2005) tackle this puzzle from two different perspectives. Fleming and Piazzesi (2005) find that yield changes depend not only on the surprises, but also on the slope of the term structure. A possible interpretation of this result is that a positive (flat) slope may indicate fears about inflation (hard landing), so that a surprise increase (decrease) in the federal fund rate may translate into lower (higher) expected inflation, thus sending long rates in the opposite direction of the short rate. Gurkaynak, Sack, and Swanson (2005), on the other hand, start from the intuition that surprises about the target rate represent only part of the news on announcement days: market participants are likely to update their beliefs about the future path of policy as well. Gurkaynak, Sack, and Swanson (2005) construct a factor that proxies for news about the future path of policy, and find that it can explain much of the variance of long term yields that is unaccounted for by surprises about the federal funds target. More recently, Andersson (2007) extends the analysis to the euro area and documents that while bond yields feature an upsurge in volatility around announcements in both US and the euro-area, the effect is more pronounced in US following Federal Reserve monetary policy decisions. Overall, the previous studies indicate that monetary policy affects yields in a quantitatively significant fashion. These results, however, are not limited to bond markets and first moments. Bernanke and Kuttner (2005) find that an unanticipated cut in the Fed rate of 25 basis points triggers a $1 \%$ increase in the stock market; Lucca and Moench (2011) document that as much as $80 \%$ of the US equity premium is earned in the 24 hours before FOMC announcements. Beber and Brandt (2006) analyze the effect of announcements on the state price densities of bond prices implied by Treasury options. They 
find that all announcements decrease the second moment of the state price density, while the effect on higher moments depends on the sign of the news. ${ }^{3}$ Importantly, both Bernanke and Kuttner (2005) and Beber and Brandt (2006) decompose the effect of announcements into their economic drivers and assess the quantitative relevance of the component due to changes in expected returns. Bernanke and Kuttner (2005) show that monetary policy shocks account for a high fraction of discount rate news; Beber and Brandt (2006), on the other hand, conclude that the results are strongly suggestive of counter-cyclical variation in relative risk aversion.

A second stream of the literature studies the link between monetary policy and bond pricing in the context of no-arbitrage term structure models. There are two popular modeling strategies. A first strategy reconciles reduced-form short-rate term structure models with the notion that most modern monetary authorities implement policy by controlling the path of the short rate. Under no arbitrage, yields are risk neutral expectations of future short rates, so that, from the perspective of no-arbitrage term structure models, introducing monetary policy amounts to specifying the mapping between short rates and state variables in a fashion that is consistent with the policy response function of the central bank. Some notable applications of this strategy are Piazzesi (2005), Ang, Dong, and Piazzesi (2007), Mönch (2008), and Chun (2011). Piazzesi (2005) obtains pricing implications for a flexible characterization of the jump process followed by the target rate; Ang, Dong, and Piazzesi (2007) explore the restrictions implied by a host of Taylor rule specifications; Chun (2011) studies the link between inflation and GDP forecasts and bond yields by incorporating survey data into a term structure model via a forward looking Taylor rule. A more ambitious task is to study monetary policy from a general equilibrium perspective. Real business cycle models that include monetary policy reactions to the real economy and endogenous inflation dynamics have proved a promising channel through which to understand the economic drivers of the nominal term structure. Since the nominal pricing kernel is given by the real pricing kernel, deflated by the inflation, the assumption that the central bank controls the nominal short rate implies a restriction on the (endogenous) inflation dynamic: the inflation process can be solved for by requiring consistency between the policy rule of the central bank and the Euler equation for the nominal short rate. For example, Kung (2014) and Gallmeyer, Hollifield, Palomino, and Zin (2007b) study Taylor rules with representative agents having Epstein-Zin preferences, while Buraschi and Jiltsov (2007) or Campbell, Pflueger, and Viceira (2013) combine habit formation and monetary policy. The general conclusion from this literature is that monetary policy and endogenous inflation dynamics help resolve many salient puzzles of the term structure with respect to models that solve for short rates in the absence of a policy rule.

\section{Data}

This section describes the data set. The sample we study is at monthly frequency and runs from January 1990 to August 2012.

\footnotetext{
${ }^{3}$ Since the authors not only consider FOMC announcements, but also 9 additional US macroeconomic news releases, it is not possible to know how results would be affected if only FOMC announcements were taken into account.
} 


\section{A. Survey data}

We use survey forecasts from BlueChip Financial Forecasts Indicators (BCFF) to construct a new measure of monetary policy shocks. ${ }^{4}$ BCFF is a monthly publication providing extensive panel data on the expectations of professional economists working at leading financial institutions and service companies. Forecasted variables include Treasury yields and economic fundamentals. While the exact timing of the surveys is not published, the survey is usually conducted between the 25th and $27 t h$ of the month and mailed to subscribers within the first 5 days of the subsequent month. The resulting dataset represents an extensive and unique dataset to investigate the role of formation of expectations about monetary policy shocks.

The horizon of BCFFS forecasts ranges from the end of the current quarter to 5 quarters ahead (6 from January 1997). We obtain a set of constant maturity forecasts (from 1 to 4 quarters ahead), by interpolating linearly between adjacent horizons. Macroeconomic forecasts are expressed as annualized percentage changes between subsequent quarters: we obtain compound growth forecasts by chaining subsequent quarterly forecasts. ${ }^{5}$

The resulting dataset of forecasts can be described as follows. Let $Z_{t}$ denote the time- $t$ realization of the economic or financial variable of interest, and let $E^{n}\left[\cdot \mid \Omega_{n, t}\right]$ denote the expectation operator under the subjective measure of agent $n$ and conditional on her time- $t$ information set $\Omega_{n, t}$. The data manipulations described above allows us to obtain $Z_{n, t, h}^{e}$, the forecast of $Z_{t+h}$ made by agent $n$ at time $t$ :

$$
Z_{n, t, h}^{e} \triangleq E^{n}\left[Z_{t+h} \mid \Omega_{n, t}\right]
$$

for quarterly horizons out to 1 year, $h=3,6,9,12$ months. Notice that this representation allows for incomplete information $\left(\Omega_{n, t}\right)$, and difference in priors about the data-generating process (the expectation is taken under the subjective measure); the only assumption is that forecasts be rational in the sense of Muth (1961). We also construct consensus forecasts $Z_{C, t, h}^{e}$, defined as the crosssectional mean of the forecasts by all respondents at time $t$ :

$$
Z_{C, t, h}^{e} \triangleq \frac{1}{N} \sum_{n=1}^{N} Z_{n, t, h}^{e},
$$

where $N$ denotes the size of the cross-section of forecasters.

The forecasts used here are real GDP (Real GNP until February 1992), Consumer Price Inflation, and the Federal Funds rate. Since real GDP, CPI, and federal funds rates are available

\footnotetext{
${ }^{4}$ Andrea Buraschi and Paul Whelan obtained the complete BCFF paper archive directly from Wolters Kluwer and proceeded to enter manually the data. The digitization process required inputting around 750,000 entries of named forecasts plus quality control checking and was completed in a joint venture with the Federal Reserve Board.

${ }^{5}$ For instance, suppose that as of April 2000, the 1Q- and 2Q-ahead GDP forecasts of agent $n$ are 5.00 and 6.00 , respectively. This means that the agent expects GDP to increase by $\left(1+\frac{5.00}{400}\right)$ between April 2000 (the month of the forecast) and June 2000 (the end of current quarter), and by $\left(1+\frac{6.00}{400}\right)$ between end of June 2000 (the end of current quarter) and the end of September 2000 (the end of the next quarter). The (annualized) compound growth rate between April 2000 and September 2000 is obtained as $\left[\left(1+\frac{5.00}{400}\right) \cdot\left(1+\frac{6.00}{400}\right)\right]^{2}$.
} 
at different frequencies (quarterly, monthly and daily, respectively), the quarterly values that the survey participants are asked to forecast are defined in different fashions. Let $G D P_{q(t)}, C P I_{m(t, j)}$, and $F F_{d(t, j)}$ denote, respectively: (i) the seasonally adjusted value of real GDP at the end of the quarter that includes month $t$; (ii) the seasonally adjusted value of CPI at the end of the $j$-th month of the quarter that includes month $t$; and (iii) the value of the federal funds rate at the end of the $j$-th day of the quarter that includes month $t$ (assumed to be 90, for simplicity). For each horizon $h$, survey participants are asked to forecast are $g_{q(t+h)}$, the quarter-over-prior-quarter percent change of seasonally-adjusted real GDP, expressed as an annualized rate:

$$
g_{q(t+h)} \triangleq\left(\frac{G D P_{q(t+h)}}{G D P_{q(t+h-1)}}\right)^{4}-1
$$

$\pi_{q(t+h)}$, the quarter-over-prior-quarter percent change of the intra-quarter average of seasonallyadjusted CPI, expressed as an annualized rate:

$$
\pi_{q(t+h)} \triangleq\left(\frac{1 / 3 \sum_{m=1}^{3} C P I_{m(t+h, j)}}{1 / 3 \sum_{j=1}^{3} C P I_{m(t+h-1, j)}}\right)^{4}-1 ;
$$

and, $f_{q(t+h)}$, the average of intra-quarter daily federal funds rates:

$$
f_{q(t+h)} \triangleq 1 / 90 \sum_{j=1}^{90} F F_{d(t+h, j)} .
$$

We denote the time- $t$ forecasts of agent $n$ for $g_{q(t+h)}, \pi_{q(t+h)}$, and $f_{q(t+h)}$ by $g_{n, t, h}^{e}, \pi_{n, t, h}^{e}$, and $f_{n, t, h}^{e}$, respectively. The online appendix plots the consensus forecasts for 1-4 quarter ahead, and the inflation GDP growth forecasts along with a macro-activity indicator that is discussed below.

We construct expected output gaps as follows. We obtain quarterly data on real GDP from the Bureau of Economic Analysis (BEA), and interpolate linearly to obtain monthly figures. We fit a Hodrick-Prescott filter (with a smoothing parameter of 14,400) to log output $y_{t}=\log \left(Y_{t}\right)$ and estimate the mean growth rate of the economy $g_{t}^{*}$ as the average log difference of output. We construct potential output $Y_{t}^{*}$ by taking the (exponential of the) trend component of the filtered series, and construct conditional estimates of future potential output (common across agents) as $E\left[Y_{t+h}^{*} \mid \Omega_{t}\right]=Y_{t}^{*} \exp \left(g_{t}^{*} \cdot h \cdot 3\right) .{ }^{6}$ Next, we obtain estimates of actual output using individual GDP growth forecasts, $E^{n}\left[Y_{t+h} \mid \Omega_{n, t}\right]=Y_{t} \cdot\left(1+\frac{g_{n, t, 1}^{e}}{400}\right) \cdot\left(1+\frac{g_{n, t, 2}^{e}}{400}\right) \ldots\left(1+\frac{g_{n, t, h}^{e}}{400}\right)$. Finally, we construct the percentage projected output gap for horizon $h$ as $x_{n, t, h}^{e}=E^{n}\left[x_{t+h} \mid \Omega_{n, t}\right]=\left(\frac{E^{n}\left[Y_{t+h} \mid \Omega_{n, t}\right]}{E\left[Y_{t+h}^{*} \mid \Omega_{t}\right]}-1\right)$. 100. Since this definition of gap may suffer from look-ahead biases, we also construct real time output gaps by fitting the Hodrick-Prescott filter and estimating mean growth rates recursively over a 10-years look-backwards rolling window. The results are only marginally affected.

\footnotetext{
${ }^{6}$ The construction of this expectations implicitly assumes that output is lognormally distributed and ignores a Jensen's inequality term, which is quantitatively negligible.
} 


\section{B. Quality of survey data}

Survey data forecasts feature a number of advantages over forecasts implied by econometric approaches such as VARs (vector autoregressions). First, the specification of the VAR may not coincide with the data generating process in the mind of the agents. Second, agents may, contrary to the econometrician, observe a structural break in the sample of interest. Third, even if both the econometrician and the agents observe the data generating process, VAR forecasts still suffer from estimation error. Survey data allows obtaining direct measures of agents' expectations, dispensing with the need to posit and estimate a data generating process for the variable of interest.

We summarize the cross-sectional and time-series properties of BCFFS expectations by comparing their performance to an econometric benchmark. In particular, we first construct the sample equivalents of the forecasts for federal funds, real GDP growth rate, and CPI growth rate. Next, we assume that the quantities of interest $\left[\begin{array}{lll}\Delta f_{t}, & g_{t}, & \pi_{t}\end{array}\right]^{\prime}$ follow a first-order VAR. We fit the VAR recursively using a 25 years rolling window (100 quarterly observations), and use the estimated parameters to construct the benchmark forecasts. Since macro-economic data are released with a month lag, we always drop the last observations when estimating the VAR to ensure that forecasts are based on the actual real-time information set of agents. Finally we compare the forecasting errors of BCFFS versus VAR(1) expectations. Figure 1 summarizes the magnitude of BCFFS forecast errors (1 quarter horizon) relative to VAR forecast errors. The plots on the left represent the errors from a cross-sectional perspective: they show the time series of the number of agents in the cross-section whose forecast error is, in absolute value, less than the absolute value of the VAR forecast error. The plots on the right, on the other hand, summarize the forecasting ability of consensus (mean) forecasts: they show the difference between the absolute value of the VAR forecast error and the absolute value of the average BCFFS forecast error, so that a value above zero means that, on a specific quarter, the consensus forecasts performs better than the VAR forecast. The figure suggests that there is a strong time-series component in the ability of BCFFS surveys to beat VAR forecasts. Overall, the errors of consensus forecasts are, in absolute value, less than the forecast error of the VAR $85 \%$ (FF), $43 \%$ (GDP), and $65 \%$ (CPI) of the times.

\section{[Insert Figure 1 about here.]}

\section{Macroeconomic activity data}

We construct a proxy for the level of macroeconomic activity by following Ludvigson and $\mathrm{Ng}$ (2009) and Buraschi and Whelan (2012). Ludvigson and Ng (2009) find strong evidence linking bond returns to variations in the level of economic growth rate factors by running return predictability regressions on the principle components from a large panel of real, nominal, and price-based variables. The identity and sources of the dataset are described in Ludvigson and $\mathrm{Ng}$ (2009); following Buraschi and Whelan (2012), we drop all price based information in order to interpret the resulting panel as a pure growth rate factor. Examples of price variables removed include: S\&P dividend yield, the Federal Funds (FF) rate; 10 year T-bond; 10 year - FF term spread; Baa - FF default 
spread; and the dollar-Yen exchange rate. A small number of discontinued macro series are replaced with appropriate alternatives or dropped. ${ }^{7}$ We take the first principle component of the resulting dataset of 99 macro series as a proxy for the conditional mean of consumption growth, $g_{t}{ }^{8}$

\section{Bond data}

We use Fama-Bliss data from CRSP of zero coupon bond prices (available at monthly frequency) with maturities between 1 and 5 years. The following notation is adopted. Define the date $t \log$ price of a n-year discount bond as $p_{t}^{(n)}$. The yield of a bond is defined as $y_{t}^{(n)}=-\frac{1}{n} p_{t}^{(n)}$. The date- $t$ 1 -year forward rate for the year from $t+n-1$ and $t+n$ is $f_{t}^{(n)}=p_{t}^{(n)}-p_{t}^{(n+1)}$. The $\log$ holding period return is the realised return on an $n$-year maturity bond bought at date $t$ and sold as an $(n-1)$-year maturity bond at date $t+12$ is denoted $r_{t+12}^{(n)}=p_{t+12}^{(n-1)}-p_{t}^{(n)}$, and the corresponding excess return is denoted $r x_{t+12}^{(n)}=r_{t+12}^{(n)}-y_{t}^{(1)}$. A table in the online appendix presents the summary statistics for bond excess returns over our sample period.

\section{Monetary policy shocks}

This section describes the methodology we use to construct monetary policy shocks. First, we provide a brief overview of the alternative approaches employed by the literature. Second, we introduce our identification scheme based on a Taylor rule and a panel of forecast data. Third, we report the statistical properties of the constructed series.

\section{A. Overview of identification schemes}

Since much of the decisions taken by the monetary authorities reflect non-monetary developments in the economy, the literature that studies the effect of monetary policy is typically concerned with policy shocks, rather than policy actions per se (Christiano, Eichenbaum, and Evans (1999)). A classic interpretation of monetary policy shocks is that they reflect changes in the preferences of the central bank, which may arise from shift in the weights of the views or political influence of the members of the policy committee (Christiano, Eichenbaum, and Evans (1999)).

In general, the strategies that seek to identify monetary policy shocks can be classified as being based on a policy rule, or not. The idea behind strategies based on policy rules is to impose as much structure on the feedback rule as needed to decompose policy actions into systematic and non-systematic components (policy shocks). In particular, researchers following this approach must make assumptions about the policy instrument, the functional form of the feedback rule, the arguments of the rule, and, importantly, the interaction of the arguments of the rule and monetary policy shocks. A common assumption, which underlies the entire literature on Taylor

\footnotetext{
${ }^{7}$ Further details of the construction and macro series included are given in the appendix of Buraschi and Whelan (2012)

${ }^{8} g_{t}$ explains around $90 \%$ of the unconditional variance of the panel of macroeconomic activity series.
} 
rules, ${ }^{9}$ is that monetary policy shocks are orthogonal to the arguments of the rule, so that they can be estimated from regression residuals. Christiano, Eichenbaum, and Evans (1999) note that the economic content of this assumption is that the macroeconomic variables that the monetary policy authority looks at in setting policy are predetermined relative to the policy shocks: these variables do not respond to contemporaneous realizations of monetary policy shocks.

The second family of identification strategies, on the other hand, infers monetary policy shocks from data that suggests exogenous monetary policy actions. An example of this identification philosophy is Romer and Romer (1989), who use historical records to identify large monetary disturbances not caused by macroeconomic developments. Similarly, Romer and Romer (2004) use quantitative and narrative records to infer intended funds rates changes around FOMC meetings, and take into account the forecasts of the Federal Reserve to remove anticipatory components. An alternative approach, pioneered by Rudebusch (1998) and employed, among others, by Kuttner (2001), Cochrane and Piazzesi (2002), Gurkaynak, Sack, and Swanson (2005), and Bernanke and Kuttner (2005), constructs monetary policy shocks from federal funds futures by exploiting their forward-looking nature. The advantage of this approach is that it overcomes the omitted-variables and time-varying parameter issues that Vector Autoregressions suffer from (Cochrane and Piazzesi $(2002))$.

\section{B. Constructing a measure of path shocks}

There are two types of monetary policy shocks: target shocks and path shocks. Target shocks represent exogenous variation in the conduct of monetary policy as reflected by the current behavior of the policy instrument (the target rate); all measures of monetary policy shocks introduced in the previous section belong to this category. Path shocks, on the other hand, capture exogenous variation in the projected path of monetary policy. Intuitively, path shocks reflect the surprises about future policy that can be inferred, for instance, from FOMC statements or interviews of members of the policy committee. Path shocks, unlike target shocks, cannot be easily identified via Taylor rule regressions because the FOMC does not reveal the projected evolution for the path of monetary policy; ${ }^{10}$ this is unfortunate, since path shocks represent the quantitatively most important source of variation in bond yields, especially for long maturities (Gurkaynak, Sack, and Swanson (2005)). Our data on federal funds forecasts, however, allows us to measure the projected evolution for the path of monetary policy from the perspective of market participants; since we also observe market participants' expectations about macroeconomic developments, we are able to identify path shocks, the exogenous variation in the path of monetary policy, by taking the residuals from a policy feedback rule estimated on federal funds and macro forecasts. This section describes the Taylor specification we adopt and discusses the restrictions it implies for forecast data.

Let $\pi_{t}$ denote the change in the price level from quarter $t-1$ to quarter $t$, annualized and in

\footnotetext{
${ }^{9}$ The literature on Taylor rules is extensive: see, for instance, Taylor (1993), Clarida, Gali, and Gertler (2000), Ang, Dong, and Piazzesi (2007).

${ }^{10}$ Recently, there has been a change in the disclosure about future policy actions; see the last subsection for a discussion.
} 
percentage points. Similarly, let $x_{t}$ denote the output gap in quarter $t$, in percentage points. As standard in the literature, the output gap is defined as $x_{t}=\left(\frac{Y_{t}}{Y_{t}^{*}}-1\right) \cdot 100$, where $Y_{t}$ and $Y_{t}^{*}$ denote actual and potential output at time $t$, respectively. Finally, let $f_{t}$ denote the time $t$ Federal Funds rate, with long run mean $f$. The level of the federal funds rate can be decomposed into a systematic component $f_{t}^{*}$ (the Taylor rule), and an orthogonal shock $u_{t}$ (the target shock):

$$
\begin{aligned}
f_{t} & =f_{t}^{*}+u_{t} \\
& =\underbrace{f+\beta\left(\pi_{t}-\pi\right)+\gamma x_{t}}_{\text {Systematic component }}+\underbrace{}_{\text {Target }{ }_{\text {shocks }}^{u_{t}},},
\end{aligned}
$$

where $u_{t} \perp f_{t}^{*}$. This characterization has a simple interpretation. The feedback rule $f_{t}^{*}$ captures the systematic component of monetary policy. In the absence of disturbances to the economy and monetary policy shocks, the federal funds rate is constant and equal to $f$. If output deviates from its potential level, or inflation from its target, the central bank intervenes to stabilize the economy: the parameters $\beta$ and $\gamma$ capture the sensitivity to inflation and output stabilization, respectively. The target shock $u_{t}$, on the other hand, captures the non-systematic component of monetary policy: the orthogonality between $u_{t}$ and the arguments of the Taylor rule means that it can be estimated as the residual of a simple time series regression of federal funds onto inflation and gap.

In practice, it has been observed that the central bank behaves less responsively to the state of the economy than implied by the benchmark Taylor rule, consistent with the idea that the central bank may have preferences over the degree of variability of federal funds rates. Also, the central bank may wish to respond to macro aggregates that are not realizing at time $t$. In order to accommodate policy inertia and backward-/forward-looking policies, the benchmark rule can be extended to include lagged federal funds and lags/leads in its arguments, so that realized federal funds rates are described by:

$$
\begin{aligned}
f_{t} & =\rho(L) f_{t-1}+(1-\rho) f_{t}^{*}+u_{t} \\
& =\underbrace{\rho(L) f_{t-1}}_{\text {Inertia }}+\underbrace{(1-\rho)\left(f+\beta\left(\pi_{t+j}-\pi^{*}\right)+\gamma x_{t+k}\right)}_{\text {Systematic }}+\underbrace{(1-\underbrace{}_{\text {shont }}}_{\text {Target }},
\end{aligned}
$$

where $\rho(L)=\rho_{1}+\rho_{2} L+\ldots \rho_{m} L^{m-1}$ and $\rho=\rho(1)$ capture the degree of interest rate smoothing. Assuming that agents know the functional form and parameters of the policy rule, while they can disagree about the future evolution of macroeconomic variables, the time- $t$ expectation of $f_{t+h}$ of agent $n$ is given by:

$$
\begin{aligned}
E^{n}\left[f_{t+h} \mid \Omega_{n, t}\right]= & E^{n}\left[\rho(L) f_{t+h-1} \mid \Omega_{n, t}\right] \\
& +(1-\rho)\left(f+\beta\left(E^{n}\left[\pi_{t+h+j} \mid \Omega_{n, t}\right]-\pi^{*}\right)+\gamma E^{n}\left[x_{t+h+k} \mid \Omega_{n, t}\right]\right) \\
& +E^{n}\left[u_{t+h} \mid \Omega_{n, t}\right],
\end{aligned}
$$


which, using the notation introduced in the data section, can be re-written as:

$$
\begin{aligned}
f_{n, t, h}^{e}= & \rho_{1} f_{n, t, h-1}^{e}+\ldots+\rho_{m} f_{n, t, h-m}^{e} \\
& +(1-\rho)\left(f+\beta\left(\pi_{n, t, h+j}^{e}-\pi^{*}\right)+\gamma x_{n, t, h+k}^{e}\right)+u_{n, t, h}^{e},
\end{aligned}
$$

or, in its consensus form, as:

$$
\begin{aligned}
& f_{C, t, h}^{e}=\underbrace{\rho_{1} f_{C, t, h-1}^{e}+\ldots+\rho_{m} f_{C, t, h-m}^{e}}_{\text {Expected }} \\
& +\underbrace{(1-\rho)\left(f+\beta\left(\pi_{C, t, h+j}^{e}-\pi^{*}\right)+\gamma x_{C, t, h+k}^{e}\right)}_{\text {Expected systematic component }}+\underbrace{u_{C, t, h}^{e}}_{\text {Path shocks }} .
\end{aligned}
$$

This expression shows that the assumption that agents believe in a Taylor rule has two implications. First, it implies a restriction on the comovement of forecasts of federal funds, inflation, output gap, and monetary policy shocks. Second, it suggests that subjective expectations about future monetary policy shocks (path shocks) can be recovered from a panel of macroeconomic and financial forecasts.

\section{Empirical features of the monetary policy shocks measure}

All the specifications examined amount to choices for $h$, the horizon of the federal funds forecasts, and $i$, the horizon of the output gap and inflation forecasts, in the general model:

$$
f_{n, t, h}^{e}=\rho_{1} f_{n, t, h-1}^{e}+\rho_{2} f_{n, t, h-2}^{e}+(1-\rho)\left(f+\beta\left(\pi_{n, t, i}^{e}-\pi^{*}\right)+\gamma x_{n, t, i}^{e}\right)+u_{n, t, h}^{e}
$$

all specifications include 2 smoothing terms, which are necessary to remove the persistent component of federal funds forecasts as in Clarida, Gali, and Gertler (2000). We consider three families of specifications based on the choice of the horizons of the forecasts for the federal funds and the arguments of the Taylor rule: 2 are contemporaneous, and 1 is forward looking. For each family, output gap is either constructed using full sample information (GAP 1), or recursively (GAP 2). This gives a total of 6 specifications, that are summarized in Table I.

\section{[Insert Table I about here.]}

In general, these models could be estimated (i) using consensus data, via OLS; or, using panel data, via: (ii) pooled OLS (POLS); (iii) fixed effects (FE); (iv) random effects (RE). We estimate the model using fixed effects and an online Appendix discusses in detail the the relationship among all estimation approaches. Table I reports the test-statistics and p-values for two tests: (i) an F-test for the joint significance of individual effects, and (ii) the Hausman test for the null hypothesis that the difference between random and fixed coefficients is not systematic. In all cases, the F-statistic for the joint significance of agent dummies rejects the null of no significance; furthermore, the Hausman test always rejects the null of random effects. Taken together, these results indicate that 
fixed effects is preferable over estimation procedures based on consensus, pooled OLS, and random effects.

Given one of the 6 Taylor rule specifications, we construct a measure of policy path shocks,

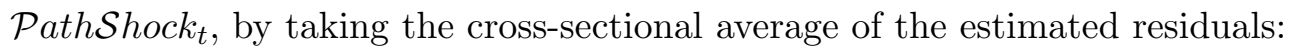

$$
\text { PathShock }_{t}=\frac{1}{N} \sum_{n=1}^{N} u_{n, t, h}^{e}
$$

The online appendix presents summary statistics for each series while figure 2 plots the time series dynamics. The message here is that, regardless of the specification, the statistical properties are very similar and the co-movement across $\mathcal{P}$ athS Shock ${ }_{t}^{i}$ is always very high. In what follows we study the economics of path shocks focusing on specification 2, in both Federal funds and macro forecasts are for the 1-year horizon, and the output gap is constructed recursively using only information available at date $t$. However, the quantitative message of the paper is robust to different choices for PathShock ${ }_{t}^{i}$. The online appendix presents an expanded set of results for all $i=1, \ldots, 6$ for what follows.

[Insert Figure 2 about here.]

\section{Path Shocks versus Target Shocks}

To help understand the information content in $\mathcal{P}_{\text {athS }}$ Shock $k_{t}$ we compare its dynamics with three alternative measures for monetary policy shocks studied by the literature: (i) the residuals from an orthogonalised monthly VAR (Christiano, Eichenbaum, and Evans (1996)); (ii) the daily change to the 1-month Federal funds futures rates around FOMC announcements (Bernanke and Kuttner (2005)); and (iii) the daily change in the 6-month euro-dollar rate around FOMC announcements (Cochrane and Piazzesi (2002)).

Firstly, we follow Christiano, Eichenbaum, and Evans (1996) and construct a monthly VAR: $B Z_{t}=A(L) Z_{t-1}+\Sigma \eta_{t}$. The data vector $Z_{t}$ is given by $Z_{t}=\left[E M P_{t}, C P I_{t}, P C O M_{t}, F F_{t}\right]$ where $E M P_{t}$ is the logarithm of Nonfarm payroll employment, $C P I_{t}$ is the logarithm of the consumer price index, and $P C O M_{t}$ is growth rate in commodity price index. We identify the system by orthogonalizing the shocks as in CEE, using the order given by $Z_{t}$. This implies that shocks to the Fed fund rate has no contemporaneous effect on the other economic variables. We specify the VAR with $L=6$ monthly lags. The estimated policy shocks are given by

$$
\eta^{c c e}(t)=i_{4} \Sigma^{-1}\left[\hat{B} Z_{t}-\hat{A}(L) Z_{t-1}\right]
$$

where $i_{4}=[0,0,0,1]$, from which we recover the policy shocks.

The second and third shock measures are based on daily data. As in Bernanke and Kuttner (2005) we measure the surprise component in target rate changes from the change in the 30Day Federal Funds Futures contract price relative to the day prior to the FOMC meeting. ${ }^{11}$ The

\footnotetext{
${ }^{11}$ These are traded on the Chicago Board of Trade where the implied futures rate is 100 minus the contract price.
} 
contract's settlement price is based on the monthly average federal funds rate so the surprise change must be scaled up by a factor related to remaining duration of the contract. Specifically, given target change on day $d$ of month $m$, we compute the unexpected target rate change as

$$
\eta^{b k}(t)=\frac{D}{D-d}\left(f_{m, d}^{0}-f_{m, d-1}^{0}\right)
$$

where $f_{m, d}^{0}$ is the current-month futures rate and $D$ is the number of days in the month. Since the effective federal funds rate tracks the target rate closely $\eta_{t}$ provides a timely measure of the surprise component to target rate changes. For the third measure, we follow Cochrane and Piazzesi (2002) and define the target shock $\eta^{c p}$ as the daily change in the 3-month euro-dollar rate around target changes

$$
\eta^{c p}(t)=\left(e_{d}^{1}-e_{m, d-1}^{1}\right)
$$

Figure 3 shows that while the three series are generally positively correlated their dynamics shows several periods in which the information content of the three series is rather different. Indeed, Cochrane and Piazzesi (2002) argue that 'If in one year the Fed worries about inflation, but in another year it places more weight on unemployment, market forecasts will adapt, but vector auto-regressions (VARs) may not adapt and thus may incorrectly interpret anticipated actions to be shocks.' The $\eta^{\text {cee }}(t)$ target shocks assume a time invariant VAR structure. While 'pure' unanticipated changes, captured by $\eta^{c p}(t)$ and $\eta^{b k}(t)$, proxy temporary variation in the preferences of the Fed, they may not convey long term information about the expected path of monetary policy. Constructing $\mathcal{P}$ athS hock $_{t}$ from surveys allows a real-time assessment of how agents expected the stance of the monetary policy to evolve over time.

To study the link between realised policy shocks and beliefs about future shocks we run regression of $\mathcal{P a t h S h o c k}_{t}$ on the three target shocks described above. Panel A of table II reports results for path shocks on target shocks, while panel B reports path shocks on a 6-month lagged summation of past target shocks. Considering first the statistical link we find slope coefficients that are consistently negative across specification for $\eta_{t}^{i}$. The estimated loads are convincingly significant, $5 / 6$ of the loadings are significant at the $1 \%$ level. While the $R^{2}$ 's of (noisy) contemporaneous shocks on path shocks are low as expected, the lagged $\eta^{c p}(t)$ and $\eta^{b y}(t)$, explain $17 \%$ and $13 \%$ of the predictable variation in $\mathcal{P} a t h \mathcal{S} h o c k_{t}$, respectively. More interesting than statistical significance we find that target shocks are negatively correlated to expectations about the future stance of policy. This is interesting since we learn a non-trivial link between observed short-term policy actions (target shocks) and the formation of expectations about future policy actions (path shocks).

In general the dependence of path shocks on target shocks could take zero, positive, negative values. If agents form expectations about future policy ignoring current actions we should expect a zero loading in table II. Alternatively, if agents believe policy shocks are subject to regime shifts and learn that they will revert in the future, the loadings should be negative. This observation is consistent with Sims and Zha (2006) who finds that variance of structural disturbances in Taylor rule regressions are subject to regime shifting components that are short lived. Alternatively, 
positive loadings could be rationalised through a number of behavioural biases such 'representativeness' (Tversky and Kahneman (1974)). In this case agents place put too much weight on recent experiences, such as a series of negative rate cuts, and extrapolate this as the likely path of policy going forward.

A revealing episode to learn about this link is given by the joint dynamics of target rate changes

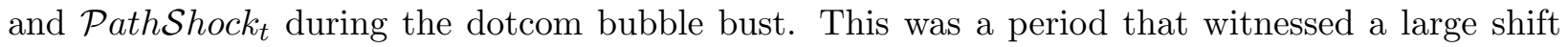
in the non-systematic component of U.S monetary policy. In 1996 Alan Greenspan, then the Chairman of the Federal Reserve, tried unsuccessfully to talk down the market in the face of an over heating technology sector. ${ }^{12}$ However, the housing market and dotcom sector rally continued. In response between June 1996 and May 2000 the Fed raised the target rate from $4.75 \%$ to 6.5\%. This represented a shift from standard Taylor rule logic since CPI inflation average just $\sim 2.20 \%$ over this period. However, the path of monetary policy was quickly reversed on September 11th 2001. In response to the Trade Center attacks the Fed acted quickly with a series of rate cuts to shore up market confidence. To support the stock market, between January 2001 and January 2002 The Fed lower the target rate from $6.5 \%$ to $1.75 \%$. The market forecast was significantly surprised by 4 of these rate changes as evidenced by the large negative realizations for both $\eta^{c p}(t)$ and $\eta^{b k}(t)$ shocks (see figure 3). However, over this period PathShock actually rose. This implies that, as market participants observed large swings in contemporaneous Taylor rule residuals, they inferred the stance of the Fed would revert in the future.

This narrative and the negative loadings in table 4 are consistent with hypothesis (3) above, in which agents learn that extreme policy response will be reversed in the future. This implies path shocks are, on average countercyclical, different than target shocks, which are procyclical. Figure 2 makes the countercyclicality of PathShockt clear by comparing the time-series dynamics of path shocks to a proxy of macroeconomic activity $\left(g_{t}\right)$ discussed in the data section above, and NBER recession dates (shaded grey areas). In all three recessions, $\mathcal{P}$ athShock $k_{t}$ rises when macroeconomic activity drops. Since bond risk premia are known to be countercyclical (Duffee (2002), Cochrane and Piazzesi (2005)), this motivates the natural question of whether its comovement with PathShock $_{t}$ is also quantitatively important, which constitutes the topic of the next section.

[Insert Figure II about here.]

[Insert Table 3 about here.]

[Insert Table 4 about here.]

\section{E. Path Shocks and Risk Premium Proxies}

To investigate whether PathShock, , extracted from macroeconomic surveys, is a potential source of priced risk, we first investigate its comovement with proxies of bond risk premia proposed by other

\footnotetext{
${ }^{12}$ Greenspan made a famous 'irrational exuberance' speech at the Francis Boyer Lecture of the American Enterprise Institute for Public Policy Research, in Washington, D.C. (Dec. 5, 1996). For the full speech see http://www.federalreserve.gov/boarddocs/speeches/19961205.htm.
} 
well-known independent studies. We consider three proxies for bond risk premia, $Z_{t}$ : (i) the slope of the yield curve as studied by Campbell and Shiller (1991) $\left(\right.$ Slope $\left._{t}=y_{t}^{(5)}-y_{t}^{(1)}\right)$; (ii) the forward rate factor of Cochrane and Piazzesi (2005) $\left(C P_{t}\right)$, and (iii) the two volatility factors constructed by Le and Singleton (2013) $\left(L S 1_{t}\right.$ and $\left.L S 2_{t}\right)$. We assess the link between path shocks via linear regressions:

$$
\text { PathShock }=\text { const. }+Z_{t}^{\prime} \beta+\epsilon_{t} \text {. }
$$

Table III presents the results of the regressions. There are two conclusions to be drawn. Regardless of the bond risk premium proxy there is a strong positive statistically significant link to $\mathcal{P}$ athShock. Firstly, consistent with the notation that path shocks are counter-cyclical the loading on the slope of the yield curve is positive, with a t-stat equal to 2.19 , and an $R^{2}$ equal to $8 \%$ : when agents expect monetary policy to revert from a loosening cycle long term bonds command risk positive risk premium. Second, PathShock co-move positively with $C P_{t}$ and $L S 2_{t}$ (t-stats above 2.2 and 2.8 , and $R^{2}$ equal to $13 \%$ and $24 \%$, respectively), suggesting that beliefs about changes to the future stance of policy are linked to contemporaneous bond risk premia. ${ }^{13}$ Figure 5 makes this point clear graphically by plotting $\mathcal{P}$ athShock versus the three risk premium proxies.

[Insert Table III about here.]

The co-movement is intriguing for a number of reasons. Since $S l o p e_{t}, C P_{t}$ and $L S 2_{t}$ are by construction spanned by the yield curve, this lends support to a link between agents subjective expectations of future monetary policy and the shape of the yield curve today. This is not obvious ex-ante since survey expectations may differ from the expectations of the marginal investor. The ability of yields to span path shocks largely depends on the relative difference in dimensions of the state vector under the physical versus agents subjective measure. Duffee (2011) discusses this point in the context of the invertibility of the current yield curve to reveal information relevant for bond risk premia. Moreover, the fact that a proxy for path shocks is correlated with a set of (spanned) risk premia proxies suggests that expectations of future monetary policy affect the shape of the yield today curve not only through physical expectations of the short rate but also through a change of measure.

\section{Bond return predictability}

This section establishes the key empirical result of the paper: path shocks drive the time variation of bond risk premia. We obtain these results via classic return predictability projections of one-year holding period bond excess returns on lagged PathShock, and test for the statistical and economic significance of the slope coefficient.

We verify the robustness of the results from a variety of perspectives. Firstly, an online appendix presents an expanded set of results for all specifications of $\mathcal{P}$ athShock, bond maturities, and subsamples. Second, we assess the statistical and economic significance of the slope coefficients

\footnotetext{
13 The factor $L S 2_{t}$ is the dominating risk premium factor in Le and Singleton (2013)
} 
in predictive regressions for bonds with maturities ranging between 2 and 5 years controlling for alternative risk factor proxies. Third, we analyze the stability of the coefficients in a subsample that excludes the crisis. Fourth, we conduct an out of sample test by checking whether PathShock is also priced in the cross-section of equity returns.

\section{A. Predictability Regressions}

Table IV reports the estimation output of regressions:

$$
r x_{t+12}^{(n)}=\text { const. }+\beta_{P S}^{(n)} \mathcal{P} a t h \mathcal{S} h o c k_{t}+\epsilon_{t+12}^{(n)} .
$$

where bond maturities $n$ range from 2 to 5 years. The estimates in the left panel are for the entire sample (the last excess return is defined between 2011:7 and 2012:7), while those on the right exclude the financial crisis (the last excess return is defined between 2007:6 and 2008:6). Reported $\bar{R}^{2}$ are adjusted, and all t-statistics employ Newey-West standard errors (18 lags); all left and right hand side variables are standardized, so that the coefficients can be interpreted as standard deviation changes of the regressand for a unit standard deviation change in the regressor. For illustrative purposes, the online appendix plots the time series of realised versus fitted (expected) excess returns for the 5-year maturity bond.

[Insert Table IV about here.]

In all projections, $\mathcal{P}$ ath $\mathcal{S}$ hock explains the time variation in bond excess returns in an economically and statistically significant fashion. Estimated slope coefficients are between 0.35 and 0.40 : a one standard deviation increase in path shocks predicts, on average, an increase of fitted excess returns by $\sim 40 \%$ of its unconditional standard deviation. Adjusted $R^{2}$ range between $12.00 \%$ and $15.53 \%$, so that monetary policy path shocks also explain a large fraction of the overall variation of realized excess returns. Also, the statistical significance is large: all t-statistics reject the null hypothesis of no predictability at the $1 \%$ level. Besides a slight decline of the economic magnitude of the slope coefficients for longer maturity bonds, there are no noticeable patterns across specifications of the right hand side variable and sample period. Overall, the results suggest that path shocks are not only a statistically and economically significant, but also robust predictor of future realized excess returns.

\section{B. Real Growth and Inflation}

Previous literature on return predictability in bond markets has highlighted the importance of real activity, which is one of the systematic ingredients of the Taylor rule. To evaluate the marginal contribution of the policy shocks versus the systematic component of the rule, we follow Ludvigson and $\mathrm{Ng}(2009)$ ) and construct a real activity factor $\left(g_{t}\right)$ from the first principle component from a large panel of macroeconomic indicators, that includes 104 individual macro time series available at monthly frequency (for details, see Section II.C.). This is different than the real argument of the 
Taylor used to estimate path shocks but is consistent with the Fed responding to deviations in real activity from a target. In addition this provides are tougher test for the marginal ability of path shocks to forecasts returns since the forecasting power of $g_{t}$ is well documented.

Table $\mathrm{V}$ repeats the predictability regressions above controlling for $g_{t}$. The loadings on $g_{t}$ are negative and significant for all maturities; both the statistical and economic significance are strongest for $n=2$ and decrease in maturity. The inclusion of $g_{t}$ in the set of regressors leads to a sizable increase in the adjusted $R^{2}$ relative to the univariate case, especially for short maturities and in the 1990-2007 sample. In the case of bonds with 2 years maturities, the average increase in $\bar{R}^{2}$ is between $10 \%$ and $15 \%$ in the 1990-2007 period, and between $5 \%$ and $10 \%$ for the full sample; the effect decreases in maturity, becoming negligible for 5 years bonds. Nevertheless, the economic and statistical significance of expected monetary policy path shocks is hardly affected. The conclusion to this section is that the information content in $\mathcal{P}$ athShock $k_{t}$ relevant for the bond risk premium is not subsumed by the contemporaneous level of macroeconomic activity.

A second potential issue is that expected inflation is endogenous to the monetary policy shocks. For instance, Gallmeyer, Hollifield, Palomino, and Zin (2007a) discuss an economy with recursive preferences and and monetary policy. In this economy inflation is endogenous to a Taylor rule which helps match the historical level of long term yields by introducing negative autocorrelation to the pricing kernel. Moreover, to the extent that monetary policy affects inflation and inflation is priced in nominal bond returns, PathShock may affect bond returns through an inflation channel. For these reasons, we run a second test controlling for consensus expectations on inflation from BlueChip surveys. Table VI summarizes the results. We find that in the sample period excluding the financial crisis, expected inflation does indeed contain marginal information on bond risk premia. The slope coefficients are positive with comparable economic magnitude of PathShock. However, PathShock retains statistical significance even after controlling for inflation. Moreover, in the sample period including the crisis, the predictable content of expected inflation disappears while $\mathcal{P}$ athShock maintains its statistical significance.

[Insert Table V and VI about here.]

\section{Predictability in the financial crisis}

Tables IV and V document that the economic and statistical significance of predictability is largely unaffected by the inclusion of the last financial crisis in the sample. This may sound, at first sight, a little surprising. Our predictor, PathShock, is based on the notion that the federal fund rate is the instrument of monetary policy, a tool that has lost its flexibility and effectiveness in the context of the ZLB (zero lower bound) characterizing the US monetary landscape since the end of $2008 .{ }^{14}$ Unable to cut federal funds targets any further, US monetary authorities have started

\footnotetext{
${ }^{14}$ During the first turmoils and Lehmans' collapse, the Fed engaged in a particularly intense series of target rate cuts: between 18 September 2007 and 16 December 2008, the target fed funds rate was decreased on each of the 10 FOMC meetings, going from 4.75\% down to a 0\%-0.25\% range. Between 16 December 2008 and December 2012, the Fed maintained the target rate in the $0 \%-0.25 \%$ range uninterruptedly.
} 
considering forward guidance ${ }^{15}$ and QE (Quantitative Easing) ${ }^{16}$ as alternative policy instruments (see Woodford (2012) for an extensive discussion).

Given such profound changes in the way that monetary policy is implemented, are measures of monetary policy shocks based on Taylor rule residuals appropriate and, more specifically, is PathShock suitable to measure exogenous variation in monetary policy? Target shocks, measured as residuals from Taylor rules estimated on current federal funds, are indeed meaningless for two reasons. First, Taylor rules imply negative nominal federal funds rates in negative GDP growth and low inflation scenarios, thus ceasing to be adequate representations of the systematic and exogenous components of monetary policy. Second, surprises about current federal funds targets are little informative about how monetary policy is actually conducted in practice, since the Federal Reserve Bank has, de facto, switched its policy instrument from current federal funds targets to forward guidance (at least temporarily). These criticisms, however, do not apply to residuals from Taylor rules estimated over expected future federal funds, and therefore to PathShock. First, despite the $0 \%-0.25 \%$ range imposed by the Fed onto current federal funds rates since December 2008, expected federal funds rates have featured noticeable volatility over the same period (see Figure ??). Second, expected future short rates are precisely the instrument of policies based on forward guidance: being a residual from a Taylor rule estimated on expectations of future short rates, $\mathcal{P}$ atShock is, by construction, a measure of the exogenous variation in forward guidance. As a consequence, $\mathcal{P}$ athShock is particularly suitable to measure exogenous monetary policy shocks in the recent monetary environment.

There is no clear interpretation of $\mathcal{P}$ athShock in terms of QE policies; nevertheless, it is interesting to study the co-movement between forward guidance and QE policies from the perspective of BCFFS survey participants. To this end, we construct measures of expected QE path shocks by looking at the change in consensus yield spreads between 1 and 4 quarter horizons. ${ }^{17}$ We consider four measures of $\mathrm{QE}$ path shocks, each based on a specific yield spread survey forecast: (i) TS5Y, $T S 10 Y, T S 30 Y$ : consensus increase in the spread between the 5-, 10-, or 30-years Treasury yield and the federal funds rate; (ii) $M T G S$ : consensus increase in the spread between the mortgage yield and the 30-years Treasury yield. We consider measures based on both Treasury and mortgage securities because the Fed has intervened in both markets during QE1 and QE2. All these measures answer the question, by how much do agents expect that Treasury or mortgage spreads will rise

\footnotetext{
${ }^{15}$ Forward guidance represents the result of a decade long process of changes in the strategy underpinning policy communication. The structure of FOMC statements has been modified to include: (i) an economic outlook, in January 2000; (ii) qualitative statements about future policy inclinations, in August 2003; (iii) calendar-based guidance, in August 2011; (iv) outcome-based guidance, in December 2012.

${ }^{16}$ Quantitative Easing policies consist of purchases, by the central bank, of specified quantities of long term financial assets. Our sample includes two instances of QE policies: (i) QE1, between late 2008 and 2009; and (ii) QE2, between the second quarters of 2010 and 2011. While QE1 consisted of purchases of MBS, Treasuries, and Agency securities, QE2 focused only on the purchase on long term Treasury securities. See Gagnon, Raskin, Remache, and Sack (2011) and Krishnamurthy and Vissing-Jorgensen (2010) for further details about QE policies and their quantitative impact on financial securities.

${ }^{17}$ As discussed earlier, any policy may be decomposed into systematic and exogenous components. Our measures of $\mathrm{QE}$, however, are not orthogonalised. In fact, there is not qualitative evidence that the Federal reserve follows a rule in implementing QE policies, and no rule could be estimated quantitatively in such a short sample (QE policies started in 2008).
} 
over the next 4 quarters? Table VII shows the pairwise correlations between $\mathcal{P}$ athShock and the four measures of QE path shocks in the full, pre-QE, and during-QE samples, taking November 2008 as the start date of the QE sample. The Table contains three interesting results. First, the correlation of $\mathcal{P}$ athShock with Treasury-based measures of QE is negative in all subsamples: when agents expect the Fed to tighten (high values of $\mathcal{P} a t h \mathcal{S} h o c k$ ), they also expect the wedge between long and short rates to decline (low values of TS5Y, TS10Y, TS30Y). Second, the correlation of PathShock with Mortgage-based measures of QE is positive in all subsamples: an expansionary forward guidance stance (low values of PathShock) is, in the mind of agents, expected to be coordinated with QE policies that aim to reduce the premium on mortgage securities (low values of $M T G S)$. Third, all correlations rise, in absolute value, in the QE-subsample, suggesting that the switch to forward guidance policies has increased the influence of the communication of the Federal Reserve onto agents' expectations.

\section{Monetary policy shocks and equity markets}

We conduct an out-of-sample test of our measure of monetary policy path shocks by asking whether it is priced in the cross-section of equity returns. The effect of monetary policy on real variables such as corporate earnings is likely to be unequal across horizons and industries. Companies may feature different sensitivities towards central bank intervention owing to, for instance, crosssectional variation in cash flow duration: if monetary policy affects only short term GDP growth, for instance, growth companies will be the least affected by tightening cycles. To the extent that investors cannot diversify away exposure to central bank intervention, monetary policy shocks may be a priced risk factor in the cross-section of equity returns. ${ }^{18}$

We follow two steps to test whether monetary policy shocks are priced in the cross-section of equity returns. First, we construct a tradable portfolio that mimics monetary policy path shocks. Second, we ask whether exposure to path shocks is marginally priced by means of cross-sectional asset pricing tests. Throughout, we use Fama and French (1993) 100 value and size portfolios (available on Kenneth French's website) as test assets.

In order to construct a portfolio that mimics monetary policy path shocks, we first run timeseries regressions of the excess returns of test portfolios $\left(R X_{t}^{i}, i=1, \ldots, 100\right)$ on $\mathcal{P}$ athShock:

$$
R X_{t}^{i}=\text { const. }+\beta_{P S}^{i} \mathcal{P a t h S h o c k}+\epsilon_{t}^{i}
$$

Next, we sort the 100 portfolios into ten deciles based on their sensitivity to monetary policy shocks $\left(\beta_{P S}^{i}\right)$, and construct the factor mimicking portfolio $m p s_{t}$ as the average of the excess returns of the top decile (Top) portfolios, minus the average of the excess returns of the bottom decile (Bottom) portfolios:

$$
m p s_{t} \triangleq \frac{1}{10} \sum_{i \in T o p} R X_{t}^{i}-\frac{1}{10} \sum_{i \in \text { Bottom }} R X_{t}^{i} .
$$

\footnotetext{
${ }^{18}$ See Palomino and $\mathrm{Li}$ (2010) for a general equilibrium model where monetary policy is a priced risk factor in the cross-section of equity returns.
} 
For reference the online appendix plots the the value and size characteristics of the portfolios used to construct $m p s_{t}$. The message from this plot is that they contain no discernible pattern on either alternative mimicking portfolio.

Next, we run standard cross-sectional, two stage, asset pricing tests. In particular, we test whether the risk premium associated with exposure to $m p s_{t}$ is significant, in an economically and statistically way, over and beyond the premia associated with Fama and French (1993) factors: $m k t_{t}$, $s m b_{t}$, and $h m l_{t}$. The first stage of the asset pricing test requires running time-series regressions of test assets' excess returns on candidate risk factors to estimate factor exposures $(\beta)$ :

$$
R X_{t}^{i}=\alpha^{i}+\beta_{m k t}^{i} m k t_{t}+\beta_{s m b}^{i} s m b_{t}+\beta_{h m l}^{i} h m l_{t}+\beta_{m p s}^{i} m p s_{t}+\epsilon_{t}^{i} .
$$

In the second stage, the prices of risk $\lambda$ associated with factor exposures $\beta$ are estimated via cross-sectional regressions of average excess returns on factor exposures:

$$
\overline{R X}^{i}=\text { const. }+\lambda_{m k t} \beta_{m k t}^{i}+\lambda_{s m b} \beta_{s m b}^{i}+\lambda_{h m l} \beta_{h m l}^{i}+\lambda_{m p s} \beta_{m p s}^{i}+\epsilon^{i}
$$

The economic and statistical significance of the prices of risk can be read off the magnitude and t-statistics of the $\lambda$ estimates. Besides standard Newey-West t-statistics, we also calculate Shanken (1992) t-statistics to account for the fact that the regressors are estimated with error in the firststage regressions.

Table VIII reports the (annualized) risk premia estimates and t-statistics for our candidate pricing factors $\left(m k t_{t}, s m b_{t}, h m l_{t}, m p s_{t}\right)$. The estimated economic significance is sizable: the $m p s_{t}$ factor commands a $4.40 \%$ premium on an annualized basis, which implies that the risk premium earned for holding monetary policy risk is second only to the market risk premium. Also the statistical significance is large. This is interesting in the light of the findings by Lucca and Moench (2011) that a large fraction of the equity risk premium is captured around the FOMC announcement days. The null hypothesis $H 0: \lambda_{m p s}=0$ is rejected at the $5 \%$ level even after control adjusting for 1st stage generated regressor problem. An online appendix repeats this test for alternative specifications for $m p s_{t}$, using one of the six specification of $\mathcal{P} a t h \mathcal{S} h o c k$ described above, and shows this result is remarkable robust. Overall, the message of Table VIII is that path shocks are a common source of priced risk not only in bond markets, but also for the cross-section of stock returns.

[Insert Table VIII about here.]

\section{Learning from predictability}

The previous sections provide robust evidence that monetary policy path shocks help to explain excess returns on bonds. This section investigates two economic channels through which path shocks may drive the time variation of bond risk premia, and asks which channel is rejected by the data. In general, risk premia are time varying if either the price or quantity of risk are not constant. 
Indeed the literature has proposed two benchmark economies that give rise to time varying risk premia: (i) habit and (ii) long-run risk (LRR) economies. Can the predictability results found in the previous section be understood within the context of one of these two streams of models?

In Lucas economies with habit preferences as in Campbell and Cochrane (1999), predictability arises in equilibrium because of an endogenously time-varying price of risk. Shocks to the current endowment affect the wedge between consumption and habit, thus inducing time-variation in the price of risk. The impact of consumption shocks on interest rates depends on the relative importance of the intertemporal consumption smoothing and precautionary savings effects. A negative shock to consumption tends to increase the short term interest rate through the consumption smoothing channel: agents expect surplus consumption to recover, so they borrow more against future consumption to smooth their consumption path. At the same time, the shock tends to reduce interest rates through a precautionary savings channel: the conditional volatility of surplus rises when its level drops, inducing agents to save more. Campbell and Cochrane (1999) parametrize the process for surplus in a way that ensures that the two effects offset each other, so that short rates are constant and the term structure of interest rates is always flat. Wachter (2006) removes this restriction and solves for bond prices. She finds that when the model is calibrated to the data, inter-temporal smoothing dominates precautionary savings: the correlation between surplus and the short rate is negative. In this context investors require compensation to hold bonds, which varies depending on the level of consumption surplus. ${ }^{19}$

In long run risk economies with Epstein and Zin (1989) recursive preferences such as Bansal and Yaron (2004), predictability stems from the dynamics of the quantity of risk: the second moments for the conditional growth rate of nominal and real macroeconomic variables are assumed to be time varying. The most recent paper that studies the implications of this class of models in bond markets is Bansal and Shaliastovich (2013). They derive a term structure model for nominal yields based on Epstein and Zin (1989) preferences, time varying expected consumption growth and inflation, time varying volatility of expected consumption growth and inflation, and money non-neutrality. In equilibrium, the impact of uncertainty on bond risk premia depends on the interaction of the sensitivity of yields to expected consumption and inflation growth and the sign of the prices of risk attached to consumption and inflation uncertainty. Nominal bond yields are increasing in both expected consumption and inflation growth. The price of expected consumption risk is positive when agents have preference for early resolution of uncertainty. Since high expected inflation signals low expected consumption growth (via money non-neutrality), the price of expected inflation risk is negative. As a consequence, while high expected growth uncertainty lowers bond premia, high expected inflation uncertainty raises bond premia.

The potential channels through which monetary path shocks can generate bond return predictability are very different in these two classes of models. Consider habit economies first. Habit economies need to feature two ingredients for expected monetary policy shocks to be a driver of risk premia: (i) monetary policy must have an impact on consumption; (ii) habit must be internal.

\footnotetext{
${ }^{19}$ Another example of habit economy is Buraschi and Jiltsov (2007), who model a continuous time economy with habit formation and obtain a closed form solution for (non-affine) bond yields.
} 
In benchmark habit economies, in fact, the dynamics of consumption are independent of monetary policy shocks. Extending the consumption dynamics from an i.i.d. process (as in Campbell and Cochrane (1999)) to accommodate money non-neutrality, ${ }^{20}$ however, is not sufficient: in external habit models, risk aversion is a function of current surplus, which in turn depends on past consumption. Thus, even if monetary policy path shocks affected future consumption, they would not affect current risk aversion and, therefore, the price of risk. In models with internal habit, on the other hand, the current marginal utility of agents also depends on future levels of consumption and habit. Thus, to the extent that expected monetary policy shocks have an impact on future consumption, they can arise as a state variable for the current level of risk aversion and price of risk. The online appendix contains a simple example that shows how money non-neutrality and internal habit can interact to induce a dependence of risk aversion on monetary policy shocks.

Next, consider a LRR economy. In LRR economies, predictability stems from macroeconomic uncertainty, i.e. heteroskedasticity in the conditional mean of consumption growth and/or inflation. For policy shocks to predict returns via a LRR channel, therefore, it must be the case that monetary policy shocks have an impact on macroeconomic uncertainty. The link between monetary policy and uncertainty has been at the centre of a heated debate: many economists, for instance, have called for the use of policy instruments and communication to explicitly target the extent of macroeconomic uncertainty. This argument has influenced the decision of introducing elements of forward guidance in the tool kit of several central bankers.

To study the implications of these two classes of models in the context of the PathShockpredictability results, we proceed in two steps. First, we compare the empirical evidence in support for a habit versus LRR economy in our sample (independently of the potential existence of monetary channel). Second, we try to understand whether the predictability we observe is consistent with a habit versus LRR channel. To this end we run two sets of regressions. In the first set of regressions, we project consumption surplus onto lagged monetary policy shocks; in the second set of regressions, we regress proxies of macroeconomic uncertainty onto contemporaneous $\mathcal{P}$ ath $\mathcal{S} h o c k$. Under the null hypothesis that a habit mechanism is at work (time-variation in the price of risk), the slope coefficient in the first regression should be negative and significant. On the other hand, if monetary path shocks generate predictability because of a long-run risk mechanism (time-variation in the quantity of risk) the slope coefficient of the second set of regressions should be positive and significant.

We follow Wachter (2006) and construct a proxy of consumption surplus $s_{t}$ as a weighted average of 10 years of monthly consumption growth rates: ${ }^{21}$

$$
s_{t}=\sum_{j=1}^{120} \phi^{j} \Delta c_{t-j},
$$

\footnotetext{
${ }^{20}$ For instance, money non neutrality may be modelled by assuming that the level of monetary policy shocks enters the conditional mean of consumption growth.

${ }^{21}$ The consumption data we use consist of seasonally adjusted, real per-capita consumption of nondurables and services (from the Bureau of Economic Analysis).
} 
where the weight is set to $\phi=0.97^{1 / 3}$ to match the quarterly autocorrelation of the $P / D$ ratio in the data, as in Wachter (2006); The left panel of figure 6 plots the dynamics of the series in our sample.

In order to construct proxies of GDP and inflation uncertainty, we use an $\operatorname{ARMA}(1,1)$ model to demean consensus expectations about 1-year ahead GDP and CPI growth, and fit a GARCH(1, 1) to the residuals: we use the conditional volatilities implied by the GARCH model as proxies of uncertainty. $^{22}$ The online appendix reports estimates for the estimated GARCH model, and the right panel of figure 6 plot the time series of the conditional volatility of GDP and inflation implied by the estimates.

[Insert table 6 about here.]

First, we compare the ability of these risk factor for bond returns. The online appendix shows the results for predictability regressions of bond excess returns on consumption surplus (left panel), macro economic uncertainty (central panel), and both consumption surplus and macro economic uncertainty (right panel). Consider first the predictive ability of habit proxies (left panel). The negative sign of the slope coefficients is intuitive: consistent with the empirical evidence that term premia are countercyclical, an increase in surplus consumption predicts a decline in future excess returns. The statistical significance, however, is weak. The null hypothesis of no significance cannot be rejected for any bond maturity. Next, consider the predictive ability of long run risk proxies (central panel). While inflation uncertainty has no forecasting ability for future excess returns, uncertainty about GDP growth features large economic and statistical significance. Contrary to Bansal and Shaliastovich (2013), we find that uncertainty about GDP growth increases, rather than decreases, bond risk premia. The right panel confirms these results by jointly considering both habit and LRR proxies.

[Insert table XV about here.]

Let us now turn to investigate the potential role played by PathShock. The online appendix reports the output of regressions of consumption surplus on lagged monetary policy path shocks. For any horizon considered $(h=1, \ldots, 5$ years), PathShock fails to predict future levels of consumption surplus, thus ruling out a habit channel. Table X, on the other hand, reports the output of regressions of macroeconomic uncertainty on contemporaneous monetary policy path shocks. The most important result in this table is that path shocks are strongly related to GDP growth uncertainty: the t-statistic rejects the null of no significance at any standard level, and the $R^{2}$ suggests that as much as one fifth of the variance of RGD uncertainty is accounted for the variation in $\mathcal{P}$ athShock. These results are consistent with two interpretations: (i) PathShock predicts future excess returns

\footnotetext{
${ }^{22}$ The construction of the proxies for conditional volatility is closely related to the methodology followed by Bansal and Shaliastovich (2013). Bansal and Shaliastovich (2013) use a VAR to demean consensus expectations about GDP growth and inflation, and then regress the sum of the squared residuals between $t$ and $t+12$ onto time- $t$ yields; the fitted values are used as a proxies of conditional variances. Our construction allows for the possibility of unspanned macro uncertainty.
} 
via a quantity of risk channel; (ii) more precisely, PathShock impacts the uncertainty surrounding GDP growth, which, consistent with a LRR economy, is a key driver of the time variation of bond risk premia in our sample (see Table XV). While the link between PathShock and $\sigma_{t}\left(g^{e}\right)$ is tight, there is a large fraction of variation in PathShock that is unrelated to fluctuations in RGD uncertainty. It is natural to ask what is the predictive power of the component of $\mathcal{P}$ athShock that is unrelated to GDP uncertainty for bond excess returns. We address this question by running predictive regressions on $\mathcal{P}$ athShock in which we control for macroeconomic uncertainty. Table XI sumarizes the results. While controlling for uncertainty does indeed reduce the forecasting power of $\mathcal{P} a t h \mathcal{S} h o c k$, path shocks retain significant forecasting power at all bond maturities.

[Insert Tables IX, X, and XI about here.]

\section{Conclusion}

Much of the term structure literature uses latent factors to model the dynamics of yields without attempting any economic interpretation (Litterman and Scheinkman (1991) and Dai and Singleton (2000)). Motivated by the link between monetary policy and the short term interest rate more recent literature has moved towards an explicit role for policy shocks within no-arbitrage term structure models (Piazzesi (2005) and Ang, Dong, and Piazzesi (2007), and Chun (2011). This paper asks a more fundamental question: does monetary policy represent a source of priced risk in bond markets and is it important for understanding time-variation in the bond risk premium?

To answer this question we construct PathShock, a measure of variation in the expected path of monetary policy. This measure is constructed in real-time from the residuals of Taylor rules estimated on survey forecasts of federal funds rates, GDP growth, and inflation. Comparing PathShock

to measures of monetary policy extracted from VAR analysis or daily shocks to short term lending rates, we find that target shocks are negatively correlated to path shocks. Since the Fed lowers the policy rate in recessions this implies path shocks are counter-cyclical and have some hope in explaining time-variation in (counter-cyclical) bond risk premia.

We study this potential link along a number of dimensions: $(i)$ we focus on well studied yield based proxies for the risk premium; and (ii) through classical predictability regressions with and without controls for alternative explanations. Summarising our findings, $\mathcal{P}$ athShock exhibits remarkable co-movement with the slope of the yield curve, the forward rate factor of Cochrane and Piazzesi (2005), and the volatility factor of Le and Singleton (2013). We find that monetary policy shocks account for 10\%-15\% of the variance of one-year excess returns for bond maturities between 2 and 5 years and are significant at the $1 \%$ level. The predictability is economically and statistically stronger after controlling for the levels of macro economic activity including the real-activity factor of Ludvigson and $\mathrm{Ng}$ (2009) and expected inflation extracted from surveys. Furthermore, the results are robust to the choice of Taylor rule specification and to the inclusion of the financial 
crisis in the sample.

These results have implications for both asset pricing and monetary policy. First, the evidence suggests that macro-finance models of the term structure should include a role for monetary policy not only through physical expectations of future short rates but also through risk-adjusted ones. Second, the results indicate that monetary authorities can learn about market expectations for the path of policy from real-time survey forecasts, and therefore represent a valuable tool in implementing policy today. 


\section{References}

Andersson, Magnus, 2007, Using intraday data to gauge financial market responses to Fed and ECB monetary policy decisions, Working Paper Series 726 European Central Bank.

Ang, Andrew, Sen Dong, and Monika Piazzesi, 2007, No-arbitrage Taylor rules, NBER Working Papers 13448 National Bureau of Economic Research, Inc.

Bansal, Ravi, and Ivan Shaliastovich, 2013, A long-run risks explanation of predictability puzzles in bond and currency markets, Review of Financial Studies 26, 1-33.

Bansal, Ravi, and Amir Yaron, 2004, Risks for the long run: A potential resolution of asset pricing puzzles, Journal of Finance 59, 1481-1509.

Beber, Alessandro, and Michael W. Brandt, 2006, The effect of macroeconomic news on beliefs and preferences: Evidence from the options market, Journal of Monetary Economics 53, 1997-2039.

Bernanke, Ben S., 2004a, The great moderation, Remarks at the meetings of the Eastern Economic Association, Washington DC, February 2004.

— 2004b, The logic of monetary policy, Remarks at the National Economists Club, Washington DC, December 2004.

— , and Kenneth N. Kuttner, 2005, What explains the stock market's reaction to Federal Reserve policy?, Journal of Finance 60, 1221-1257.

Buraschi, Andrea, and Alexei Jiltsov, 2007, Habit formation and macroeconomic models of the term structure of interest rates, Journal of Financeinance 62, 3009-3063.

Buraschi, Andrea, and Paul Whelan, 2012, Term Structure Models with Differences in Beliefs, Imperial College Business School Working Paper.

Campbell, John Y., and John H. Cochrane, 1999, By force of habit: a consumption-based explanation of aggregate stock market behavior, Journal of Political Economy 107, 205-251.

Campbell, John Y, Carolin Pflueger, and Luis M Viceira, 2013, Monetary policy drivers of bond and equity risks, Unpublished manuscript, Harvard University.

Campbell, John Y., and Robert J. Shiller, 1991, Yield spreads and interest rate movements: A bird's eye view, Review of Economic Studies 58, 495-514.

Christiano, Lawrence, Martin Eichenbaum, and Charles Evans, 1996, The effects of monetary policy shocks: some evidence from the flow of funds, The Review of Economics and Statistics 78, 16-34.

Christiano, Lawrence J., Martin Eichenbaum, and Charles L. Evans, 1999, Monetary policy shocks: What have we learned and to what end?, in J. B. Taylor, and M. Woodford, ed.: Handbook of Macroeconomicsvol. 1 of Handbook of Macroeconomics . chap. 2, pp. 65-148 (Elsevier). 
Chun, Albert L., 2011, Expectations, bond yields, and monetary policy, Review of Financial Studies $24,208-247$.

Clarida, Richard, Jordi Gali, and Mark Gertler, 2000, Monetary policy rules and macroeconomic stability: Evidence and some theory, The Quarterly Journal of Economics 115, 147-180.

Cochrane, John H., and Monika Piazzesi, 2002, The fed and interest rates - a high-frequency identification, American Economic Review 92, 90-95.

— , 2005, Bond risk premia, American Economic Review 95, 138-160.

Constantinides, George, 1990, Habit formation: a resolution of the equity premium puzzle, Journal of Political Economy 98, 519 - 543.

Dai, Qiang, and Kenneth J Singleton, 2000, Specification analysis of affine term structure models, The Journal of Finance 55, 1943-1978.

Duffee, Gregory R, 2002, Term premia and interest rate forecasts in affine models, The Journal of Finance 57, 405-443.

Duffee, Gregory R., 2011, Information in (and not in) the term structure, Review of Financial Studies 24, 2895-2934.

Epstein, Larry G., and Stanley E. Zin, 1989, Substitution, risk aversion, and the temporal behavior of consumption and asset returns: A theoretical framework, Econometrica 57, pp. 937-969.

Fama, Eugene F., and Kenneth R. French, 1993, Common risk factors in the returns on stocks and bonds, Journal of Financial Economics 33, 3-56.

Fleming, Michael, and Monika Piazzesi, 2005, Monetary policy tick by tick, Stanford University working paper.

Gagnon, Joseph, Matthew Raskin, Julie Remache, and Brian Sack, 2011, Large-scale asset purchases by the Federal Reserve: Did they work?, Economic Policy Review 17, 41-59.

Gallmeyer, Michael F, Burton Hollifield, Francisco Palomino, and Stanley E Zin, 2007a, Arbitragefree bond pricing with dynamic macroeconomic models, Discussion paper, National Bureau of Economic Research.

Gallmeyer, Michael F., Burton Hollifield, Francisco J. Palomino, and Stanley E. Zin, 2007b, Arbitrage-free bond pricing with dynamic macroeconomic models, Federal Reserve Bank of St. Louis Review, July 2007 pp. 305-326.

Gurkaynak, Refet S., Brian Sack, and Eric Swanson, 2005, Do actions speak louder than words? the response of asset prices to monetary policy actions and statements, International Journal of Central Banking 1, 55-93. 
Heaton, John C., 1995, An empirical investigation of asset pricing with temporally dependent preference specifications, Econometrica 63, 681-717.

King, Robert G., 2000, The new IS-LM model : language, logic, and limits, Economic Quarterly, Summer 2000 pp. 45-103.

Krishnamurthy, Arvind, and Annette Vissing-Jorgensen, 2010, The effects of quantitative easing on long term interest rates, Kellogg School of Management working paper.

Kung, Howard, 2014, Macroeconomic linkages between monetary policy and the term structure of interest rates, Journal of Financial Economics, forthcoming.

Kuttner, Kenneth N., 2001, Monetary policy surprises and interest rates: Evidence from the fed funds futures market, Journal of Monetary Economics 47, 523-544.

Le, Anh, and Kenneth J. Singleton, 2013, The structure of risks in equilibrium affine models of bond yields, Stanford University working paper.

Litterman, Robert B, and Jose Scheinkman, 1991, Common factors affecting bond returns, The Journal of Fixed Income 1, 54-61.

Lucca, David O., and Emanuel Moench, 2011, The pre-FOMC announcement drift, Staff Reports 512 Federal Reserve Board Working Paper.

Ludvigson, Sydney C., and Serena Ng, 2009, Macro factors in bond risk premia, Review of Financial Studies 22, 5027-5067.

Mönch, Emanuel, 2008, Forecasting the yield curve in a data-rich environment: A no-arbitrage factor-augmented var approach, Journal of Econometrics 146, 26-43.

Muth, John A., 1961, Rational Expectations and the Theory of Price Movements, Econometrica $29,315-335$.

Palomino, Francisco, and Erica Li, 2010, Monetary policy risk and the cross-section of stock returns, 2010 Meeting Papers 935 Society for Economic Dynamics.

Piazzesi, Monika, 2005, Bond yields and the Federal Reserve, Journal of Political Economy 113, $311-344$.

Romer, Christina D., and David H. Romer, 1989, Does monetary policy matter? A new test in the spirit of Friedman and Schwartz, in NBER Macroeconomics Annual 1989, Volume 4NBER Chapters . pp. 121-184 (National Bureau of Economic Research, Inc).

— 2004, A new measure of monetary shocks: Derivation and implications, American Economic Review 94, 1055-1084. 
Rudebusch, Glenn D., 1998, Do measures of monetary policy in a var make sense?, International Economic Review 39, 907-31.

Santos, Tano, and Pietro Veronesi, 2010, Habit formation, the cross section of stock returns and the cash-flow risk puzzle, Journal of Financial Economics 98, 385-413.

Shanken, Jay, 1992, On the estimation of beta-pricing models, Review of Financial Studies 5, 1-33.

Sims, Christopher A, and Tao Zha, 2006, Were there regime switches in us monetary policy?, The American Economic Review pp. 54-81.

Sundaresan, Suresh, 1989, Intertemporally dependent preferences and the volatility of consumption and wealth, Review of Financial Studies 2, 73-89.

Taylor, John B., 1993, Discretion versus policy rules in practice, in Carnegie-Rochester conference series on public policy vol. 39 pp. 195-214. Elsevier.

Tversky, Amos, and Daniel Kahneman, 1974, Judgment under uncertainty: Heuristics and biases, science $185,1124-1131$.

Wachter, Jessica A., 2006, A consumption-based model of the term structure of interest rates, Journal of Financial Economics 79, 365-399.

Woodford, Michael, 2012, Methods of policy accommodation at the interest-rate lower bound, working paper Columbia University. 


\section{Appendix B: Tables}

Table I. Taylor rule specifications

This table describes different specifications of the general Taylor rule model

$$
f_{n, t, h}^{e}=\rho_{1} f_{n, t, h-1}^{e}+\rho_{2} f_{n, t, h-2}^{e}+(1-\rho)\left(f+\beta\left(\pi_{n, t, i}^{e}-\pi^{*}\right)+\gamma x_{n, t, i}^{e}\right)+u_{n, t, h}^{e} .
$$

The first row contains the horizon, in months, of the federal funds rate forecast. The second row contains the horizon, in months, of inflation and output gap forecasts. The third row describes the type of output gap employed; output gap 1 is constructed using full sample information, while output gap 2 is constructed recursively. The fourth and fifth rows report the test-statistic and p-value of the F-test for the joint significance of the individual effects. The final two rows report the test-statistic and p-value of the Hausman test for systematic differences between random and fixed effects coefficients (null hypothesis: random effects is appropriate).

\begin{tabular}{lcccccc}
\hline Specification & $\mathbf{1}$ & $\mathbf{2}$ & $\mathbf{3}$ & $\mathbf{4}$ & $\mathbf{5}$ & $\mathbf{6}$ \\
\hline $\mathrm{h}$ & 12 & 12 & 9 & 9 & 9 & 9 \\
$\mathrm{i}$ & 12 & 12 & 9 & 9 & 12 & 12 \\
$\mathrm{GAP}$ & 1 & 2 & 1 & 2 & 1 & 2 \\
$\mathrm{~F}(\mathrm{FE})$ & 7.69 & 7.56 & 8.86 & 8.85 & 8.19 & 8.31 \\
& 0.00 & 0.00 & 0.00 & 0.00 & 0.00 & 0.00 \\
Hausman & 52.91 & 50.61 & 32.71 & 37.17 & 31.28 & 36.23 \\
& 0.00 & 0.00 & 0.00 & 0.00 & 0.00 & 0.00 \\
\hline
\end{tabular}


Table II. Path Shocks vs Target Shocks

Table reports results of a regression of $\mathcal{P} a t h \mathcal{S} h o c k_{t}$ on test three proxies for target shocks that have been studied in the literature: $(i)$ the residuals in a monthly orthogonalised VAR $\left(\eta_{t}^{\text {cee }}\right)$; (ii) the 1-day change in the 3 month euro-dollar rate around FOMC announcements $\left(\eta_{t}^{c p}\right)$; and $(i i i)$ the 1-day change in the 1-month Federal funds futures rate around FOMC announcements $\eta_{t}^{b k}$. Panel A reports loadings, t-statistics (White standard errors) and $R^{2}$ from

$$
\text { PathShock }_{t}=\alpha+\beta \eta_{t}^{i}+\varepsilon_{t}
$$

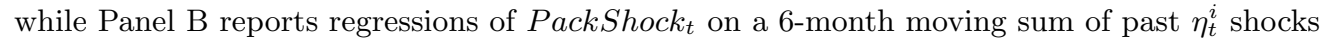

$$
\text { PathShock }_{t}=\alpha+\beta \sum_{k=1}^{6} \eta_{t-k+1}^{i}+\varepsilon_{t}
$$

\begin{tabular}{lccc}
\hline & $\eta_{t}^{c e e}$ & $\eta_{t}^{c p}$ & $\eta_{t}^{b k}$ \\
\hline \multicolumn{4}{c}{ Panel A } \\
\hline$\beta$ & -0.04 & -0.03 & -0.04 \\
t-stat & $(-2.03)$ & $(-0.99)$ & $(-4.70)$ \\
$R^{2}$ & 0.02 & 0.01 & 0.03 \\
\hline \multicolumn{4}{c}{ Panel B } \\
\hline$\beta$ & -0.02 & -0.06 & -0.03 \\
t-stat & $(-2.77)$ & $(-4.97)$ & $(-4.43)$ \\
$R^{2}$ & 0.06 & 0.15 & 0.10 \\
\hline
\end{tabular}

Table III. Risk Premium Proxies

The table reports the results from regressions of $\mathcal{P}$ ath $S$ hock on bond risk premia proxies extracted from date $t$ yield curve information:

$$
\text { PathShock } k_{t}=\text { const. }+\beta Z_{t}^{\prime}+\epsilon_{t}
$$

The proxies for yield based risk premium proxies $Z_{t}$ are the slope of the yield curve as in Campbell and Shiller (1991) $\left(\right.$ Slope $\left._{t}=y_{t}^{(5)}-y_{t}^{(1)}\right)$, the forward rate factor of Cochrane and Piazzesi $(2005)\left(C P_{t}\right)$, and the two volatility factors estimated by Le and Singleton (2013) ( $L S 1_{t}$ and $\left.L S 2_{t}\right)$. T-statistics, reported below in parenthesis are corrected for auto-correlation and heteroskedasticity using Newey-West errors (18 lags). Both left and right hand variables are standardized. A constant is included but not reported. Sample period: 1990:1 - 2007:12.

\begin{tabular}{lccccc}
\hline & Slope $_{t}$ & $C P_{t}$ & $L S 1_{t}$ & $L S 2_{t}$ & $R^{2}$ \\
\hline$\beta$ & 0.29 & & & & 0.08 \\
t-stat & $(2.19)$ & & & & \\
$\beta$ & & 0.36 & & & 0.12 \\
t-stat & & $(3.03)$ & & & \\
$\beta$ & & & 0.06 & 0.52 & 0.23 \\
t-stat & & & $(0.32)$ & $(2.94)$ & \\
\hline
\end{tabular}


Table IV. Bond Return Predictability: PathShock

The table reports the output from regressions of annual bond excess returns on a constant and expected monetary policy shocks:

$$
r x_{t+12}^{(n)}=\text { const. }+\beta_{P S}^{(n)} \mathcal{P} \text { athShock } \text { s }_{t}+\epsilon_{t+12}^{(n)} .
$$

Bond maturities $(n)$ range from 2 to 5 years. Each panel reports the results for one of the 6 proxies of expected monetary policy described by Table I. The left panels report the results for the full sample (the last observation is the excess return that realized between 2011:7 and 2012:7), while the right panels report the results for the sample excluding the crisis (the last observation is the excess return that realized between 2007:6 and 2008:6). T-statistics, reported below in parenthesis are corrected for auto-correlation and heteroskedasticity using Newey-West errors (18 lags). $\bar{R}^{2}$ is the adjusted $R^{2}$. Both left and right hand variables are standardized. A constant is included but not reported.

\begin{tabular}{ccccc}
\hline & \multicolumn{2}{c}{$1990-2011$} & \multicolumn{2}{c}{$1990-2007$} \\
$n$ & PathShock & $\bar{R}^{2}$ & PathShock & $\bar{R}^{2}$ \\
\hline 2 & 0.38 & $14.00 \%$ & 0.40 & $15.53 \%$ \\
& $(3.13)$ & & $(3.07)$ & \\
3 & 0.37 & $13.73 \%$ & 0.39 & $14.62 \%$ \\
& $(3.19)$ & & $(3.00)$ & \\
4 & 0.38 & $14.05 \%$ & 0.38 & $13.70 \%$ \\
& $(3.35)$ & & $(2.89)$ & \\
5 & 0.35 & $12.05 \%$ & 0.35 & $12.00 \%$ \\
& $(3.19)$ & & $(2.77)$ & \\
\hline
\end{tabular}

Table V. Bond Return Predictability: PathShock and $g_{t}$

The table reports the output from regressions of annual bond excess returns on a constant, expected monetary policy shocks, and levels of macroeconomic activity:

$$
r x_{t+12}^{(n)}=\text { const }+\beta_{P S}^{(n)} \mathcal{P} \text { athShock }+\beta_{g}^{(n)} g_{t}+\epsilon_{t+12}^{(n)}
$$

Bond maturities $(n)$ range from 2 to 5 years. The left panels report the results for the full sample (the last observation is the excess return that realized between 2011:7 and 2012:7), while the right panels report the results for the sample excluding the crisis (the last observation is the excess return that realized between 2007:6 and 2008:6). T-statistics, reported below in parenthesis are corrected for auto-correlation and heteroskedasticity using Newey-West errors (18 lags). $\bar{R}^{2}$ is the adjusted $R^{2}$. Both left and right hand variables are standardized. A constant is included but not reported.

\begin{tabular}{ccccccc}
\hline & \multicolumn{3}{c}{$1990-2011$} & & \multicolumn{3}{c}{$1990-2007$} \\
$n$ & PathShock & $g$ & $\bar{R}^{2}$ & PathShock & $g$ & $\bar{R}^{2}$ \\
\hline 2 & 0.35 & -0.31 & $22.97 \%$ & 0.23 & -0.40 & $28.04 \%$ \\
& $(3.32)$ & $(-2.70)$ & & $(1.85)$ & $(-4.24)$ & \\
3 & 0.35 & -0.28 & $21.16 \%$ & 0.25 & -0.32 & $22.54 \%$ \\
& $(3.30)$ & $(-2.89)$ & & $(1.95)$ & $(-3.57)$ & \\
4 & 0.36 & -0.23 & $18.89 \%$ & 0.26 & -0.26 & $18.78 \%$ \\
& $(3.27)$ & $(-2.41)$ & & $(2.00)$ & $(-3.00)$ & \\
5 & 0.33 & -0.20 & $15.90 \%$ & 0.27 & -0.19 & $14.45 \%$ \\
& $(3.10)$ & $(-2.50)$ & & $(2.08)$ & $(-2.32)$ \\
\hline
\end{tabular}


Table VI. Bond Return Predictability: PathShock and $E\left[\pi_{t}\right]$

The table reports the output from regressions of annual bond excess returns on a constant, expected monetary policy shocks, the consensus forecast for the $4 \mathrm{Q}$-ahead ahead rate of inflation activity:

$$
r x_{t+12}^{(n)}=\text { const }+\beta_{P S}^{(n)} \mathcal{P a t h S h o c k}+\beta_{g}^{(n)} E\left[\pi_{t}\right]+\epsilon_{t+12}^{(n)}
$$

Bond maturities $(n)$ range from 2 to 5 years. The left panels report the results for the full sample (the last observation is the excess return that realized between 2011:7 and 2012:7), while the right panels report the results for the sample excluding the crisis (the last observation is the excess return that realized between 2007:6 and 2008:6). T-statistics, reported below in parenthesis are corrected for auto-correlation and heteroskedasticity using Newey-West errors (18 lags). $\bar{R}^{2}$ is the adjusted $R^{2}$. Both left and right hand variables are standardized. A constant is included but not reported.

\begin{tabular}{lcccccc}
\hline & \multicolumn{3}{c}{$1990-2011$} & \multicolumn{3}{c}{$1990-2007$} \\
$n$ & PathShock & $E\left[\pi_{t}\right]$ & $\bar{R}^{2}$ & PathShock & $E\left[\pi_{t}\right]$ & $\bar{R}^{2}$ \\
\hline $\operatorname{rx}(2)$ & 0.35 & 0.29 & 0.22 & 0.39 & 0.39 & 0.30 \\
& $(2.94)$ & $(2.36)$ & & $(3.20)$ & $(3.05)$ & \\
$\operatorname{rx}(3)$ & 0.36 & 0.21 & 0.18 & 0.38 & 0.32 & 0.25 \\
& $(2.95)$ & $(1.64)$ & & $(2.88)$ & $(2.45)$ & \\
$\operatorname{rx}(4)$ & 0.36 & 0.18 & 0.17 & 0.37 & 0.31 & 0.23 \\
& $(3.12)$ & $(1.43)$ & & $(2.74)$ & $(2.35)$ & \\
$\operatorname{rx}(5)$ & 0.34 & 0.12 & 0.13 & 0.35 & 0.28 & 0.19 \\
& $(3.01)$ & $(0.93)$ & & $(2.59)$ & $(2.10)$ & \\
\hline
\end{tabular}

Table VII. PathShocks and QE path shocks

The table reports the correlation of PathShocks with four measures of QE path shocks: TS5y, TS10y, $T S 30 y$, and MTGS. The first, second, and third rows report the pairwise correlations for the full, pre-QE (up until November 2008), and QE sample (after November 2008), respectively.

\begin{tabular}{lccccc}
\hline Sample period & TS5y & TS10y & TS30y & MTGS & nobs \\
Full sample & $-0,21$ & $-0,28$ & $-0,31$ & 0,20 & 264 \\
Pre-QE & $-0,06$ & $-0,14$ & $-0,19$ & 0,09 & 226 \\
During QE & $-0,83$ & $-0,91$ & $-0,89$ & 0,43 & 38 \\
\hline
\end{tabular}


Table VIII. Monetary Policy Shocks and Equity Returns

The table reports risk premium estimates $(\lambda)$ for the 4-factor equity asset pricing model $E\left[R X^{i}\right]=\beta^{i \prime} \lambda$. The candidate risk factors are the market excess return (mkt), Fama and French (1993) value and size factors $(s m b$ and $h m l)$ and the portfolio mimicking monetary policy shocks (mps):

$$
\begin{aligned}
\beta^{i \prime} & =\left[\begin{array}{llll}
\beta_{m k t}^{i} & \beta_{s m b}^{i} & \beta_{h m l}^{i} & \beta_{m p s}^{i}
\end{array}\right]^{\prime} \\
\lambda^{\prime} & =\left[\begin{array}{llll}
\lambda_{m k t} & \lambda_{s m b} & \lambda_{h m l} & \lambda_{m p s}
\end{array}\right]^{\prime}
\end{aligned}
$$

Factor betas are estimated in first-stage time series regressions via OLS. For each specification: the first row reports (annualized) risk premia estimates; the second row reports t-statistics corrected for auto-correlation and heteroskedasticity using Newey-West errors (18 lags); the third row reports t-statistics that employ Shanken (1992) correction. Sample period: 1990:1 - 2011:7.

\begin{tabular}{cccc}
\hline$m k t$ & $s m b$ & $h m l$ & $m p s$ \\
\hline $5.99 \%$ & $2.52 \%$ & $3.79 \%$ & $4.40 \%$ \\
$(8.69)$ & $(4.52)$ & $(2.90)$ & $(5.03)$ \\
$(1.77)$ & $(0.95)$ & $(1.50)$ & $(2.17)$ \\
\hline
\end{tabular}

Table IX. Monetary Policy Shocks and Surplus

The table reports the output from regressions of consumption surplus at time $t+h\left(s_{t+h}\right)$ on expected monetary policy shocks at time $t$ :

$$
s_{t+h}=\text { const. }+\beta \mathcal{P} \text { athShock } \text { s }_{t}+\epsilon_{t+12}
$$

Forecasting horizons $(h)$ range from 1 to 5 years. T-statistics, reported below the point estimates, are corrected for auto-correlation and heteroskedasticity using Newey-West errors (lags equal to $h$ ). $\bar{R}^{2}$ is the adjusted $R^{2}$. Both left and right hand variables are standardized. A constant is included but not reported.

\begin{tabular}{ccc}
\hline$h$ & PathShock & $\bar{R}^{2}$ \\
\hline 1 & -0.01 & 0.00 \\
& $(-0.09)$ & \\
2 & 0.02 & 0.00 \\
& $(0.13)$ & \\
3 & 0.16 & 0.02 \\
& $(0.83)$ & \\
4 & 0.29 & 0.04 \\
& $(1.21)$ & \\
5 & 0.11 & 0.01 \\
& $(0.50)$ & \\
\hline
\end{tabular}


Table X. Monetary Policy Shocks and Uncertainty

The table reports the output from regressions of macroeconomic (GDP, inflation) uncertainty at time $t$ $\left(\sigma_{t}(\cdot)\right)$ on monetary policy path shocks (specification 1$)$ at time $t$ :

$$
\sigma_{t}(\cdot)=\text { const. }+\beta \mathcal{P} \text { athShock } \text { s }_{t}+\epsilon_{t}
$$

T-statistics, reported below the point estimates, are corrected for auto-correlation and heteroskedasticity using Newey-West errors (18 lags equal). $\bar{R}^{2}$ is the adjusted $R^{2}$. Both left and right hand variables are standardized. A constant is included but not reported.

\begin{tabular}{ccc}
\hline & PathShock & $\bar{R}^{2}$ \\
\hline$\sigma\left(g^{e}\right)$ & 0,46 & $20,50 \%$ \\
& 3,27 & \\
$\sigma\left(\pi^{e}\right)$ & 0,15 & $2,00 \%$ \\
& 0,98 & \\
\hline
\end{tabular}

Table XI. Monetary Policy Shocks versus Uncertainty

The table reports the output from regressions of annual bond excess returns on monetary policy path shocks, controlling for the level of macroeconomic activity and uncertainty:

$$
r x_{t+12}^{(n)}=\text { const. }+\beta_{P S}^{(n)} \mathcal{P} a t h \mathcal{S} h o c k_{t}+\beta_{g}^{(n)} g_{t}+\beta_{\sigma(g)}^{(n)} \sigma_{t}\left(g^{e}\right)+\beta_{\sigma(\pi)}^{(n)} \sigma_{t}\left(\pi^{e}\right)+\epsilon_{t+12}^{(n)}
$$

Bond maturities $(n)$ range from 2 to 5 years. T-statistics, reported below the point estimates, are corrected for auto-correlation and heteroskedasticity using Newey-West errors (18 lags). $\bar{R}^{2}$ is the adjusted $R^{2}$. Both left and right hand variables are standardized. A constant is included but not reported.

\begin{tabular}{cccccc}
\hline$n$ & PathShock & $g$ & $\sigma\left(g^{e}\right)$ & $\sigma\left(\pi^{e}\right)$ & $\bar{R}^{2}$ \\
\hline 2 & 0.30 & -0.23 & 0.16 & -0.02 & 0.24 \\
& $(2.47)$ & $(-1.88)$ & $(1.30)$ & $(-0.23)$ & \\
3 & 0.28 & -0.17 & 0.23 & -0.03 & 0.24 \\
& $(2.27)$ & $(-1.58)$ & $(1.98)$ & $(-0.50)$ & \\
4 & 0.27 & -0.11 & 0.27 & -0.05 & 0.22 \\
& $(2.19)$ & $(-1.15)$ & $(2.46)$ & $(-0.82)$ & \\
5 & 0.25 & -0.08 & 0.28 & -0.05 & 0.20 \\
& $(1.98)$ & $(-0.88)$ & $(2.81)$ & $(-0.90)$ & \\
\hline
\end{tabular}




\section{Appendix C: Figures}
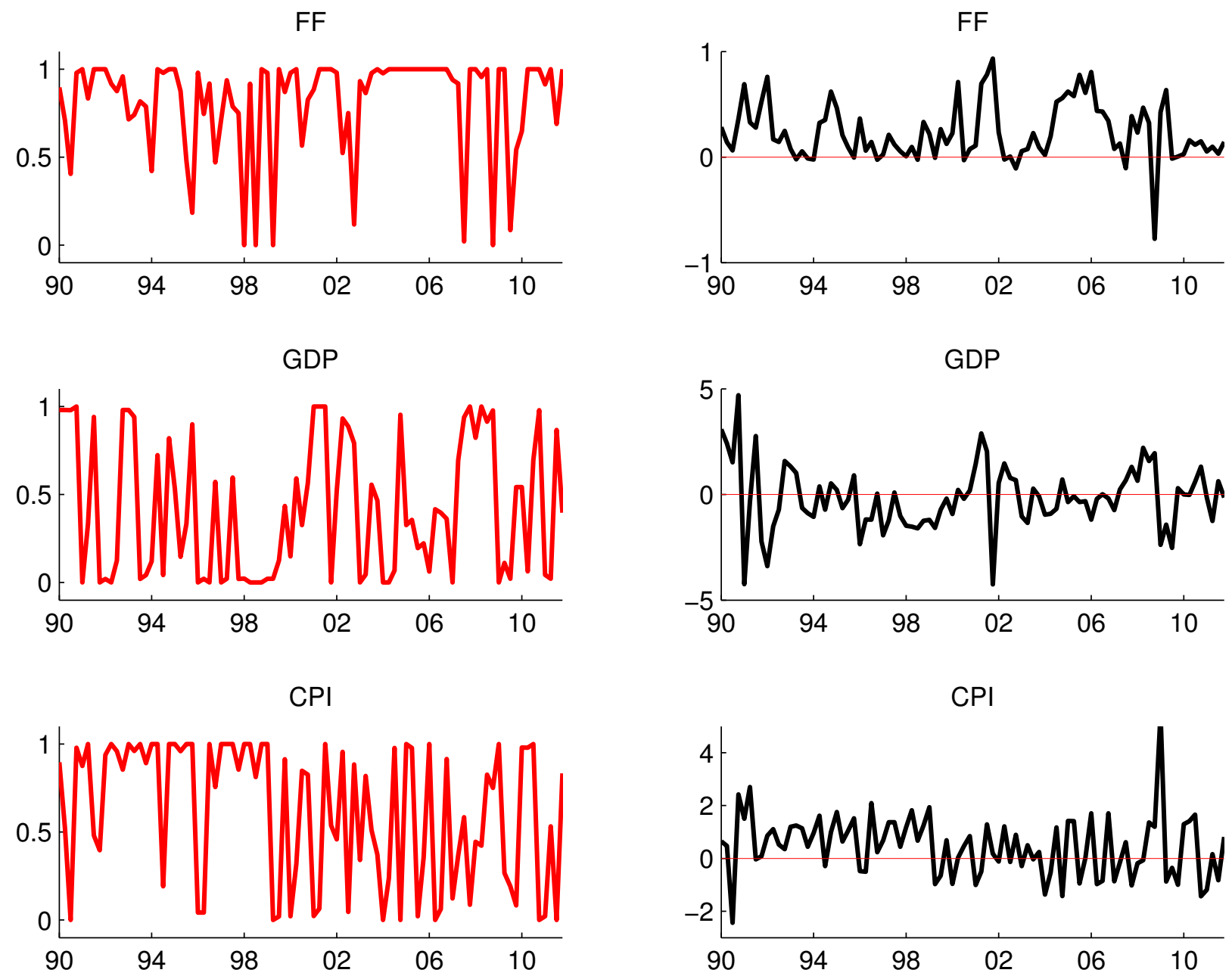

Figure 1. The Performance of BCFFS Forecasts

The figure plots the time series of the number of agents in the cross-section whose forecast error is, in absolute value, less than the absolute value of the VAR forecast error (left panels), and the difference between the absolute value of the VAR forecast error and the absolute value of the average BCFFS forecast error (right panels). Forecast horizon: one quarter. 


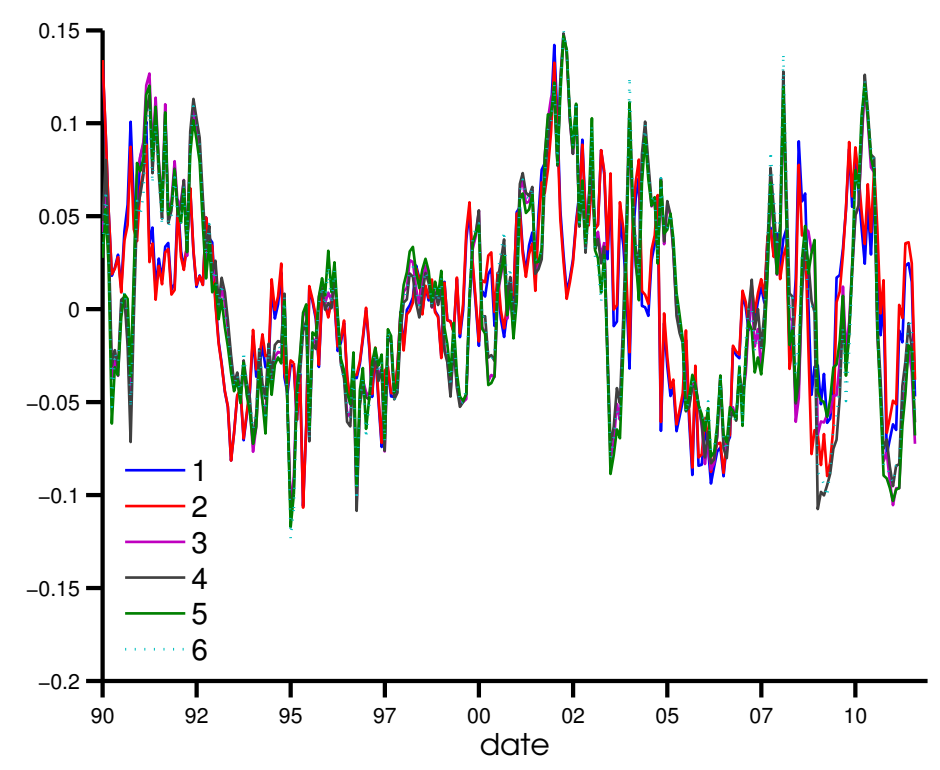

Figure 2. PathShock

This figure plots monetary policy path shocks $\mathcal{P} a t h \mathcal{S} h o c k$, constructed as cross-sectional averages of the residuals from Taylor rules estimated over a panel of forecast data. Each series corresponds to one of the 6 specifications described in Table I. Sample period: 1990:1 - 2011:7.

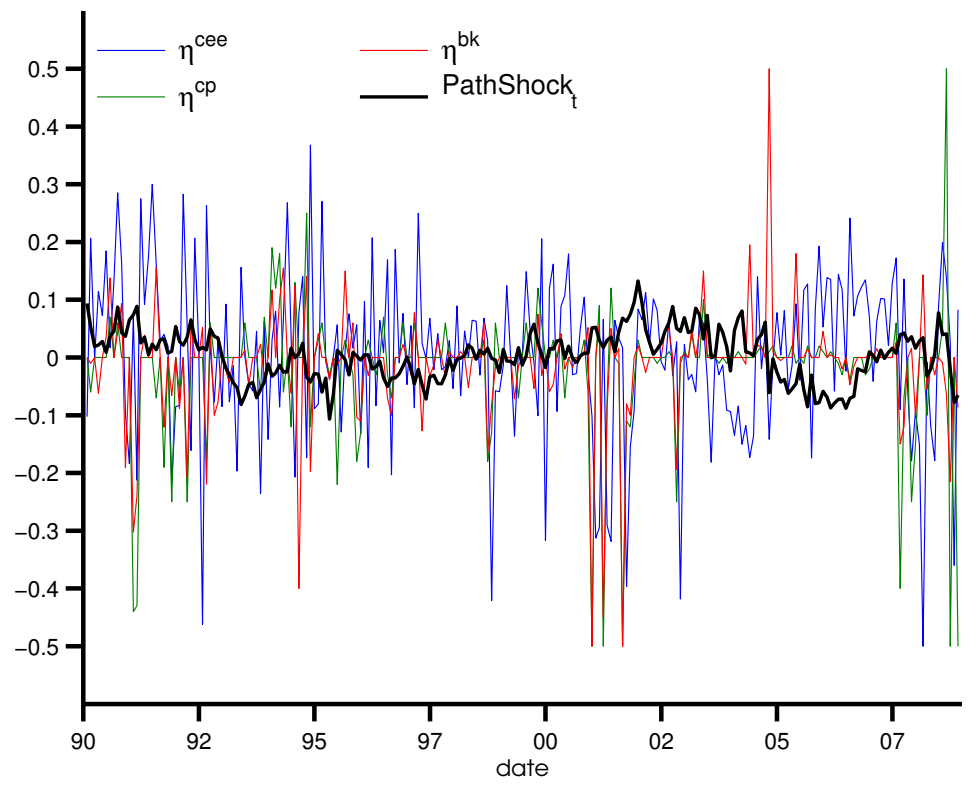

Figure 3. Comparing Shocks:

Figure plots $\mathcal{P}$ athS Shock against three proxies for target shocks proposed by the literature: $(i)$ the residuals in a monthly orthogonalised $\operatorname{VAR}\left(\eta_{t}^{\text {cee }}\right)$; (ii) the 1-day change in the 3 month euro-dollar rate around FOMC announcements $\left(\eta_{t}^{c p}\right)$; and $(i i i)$ the 1-day change in the 1-month Federal funds futures rate around FOMC announcements $\left(\eta_{t}^{b k}\right)$. 


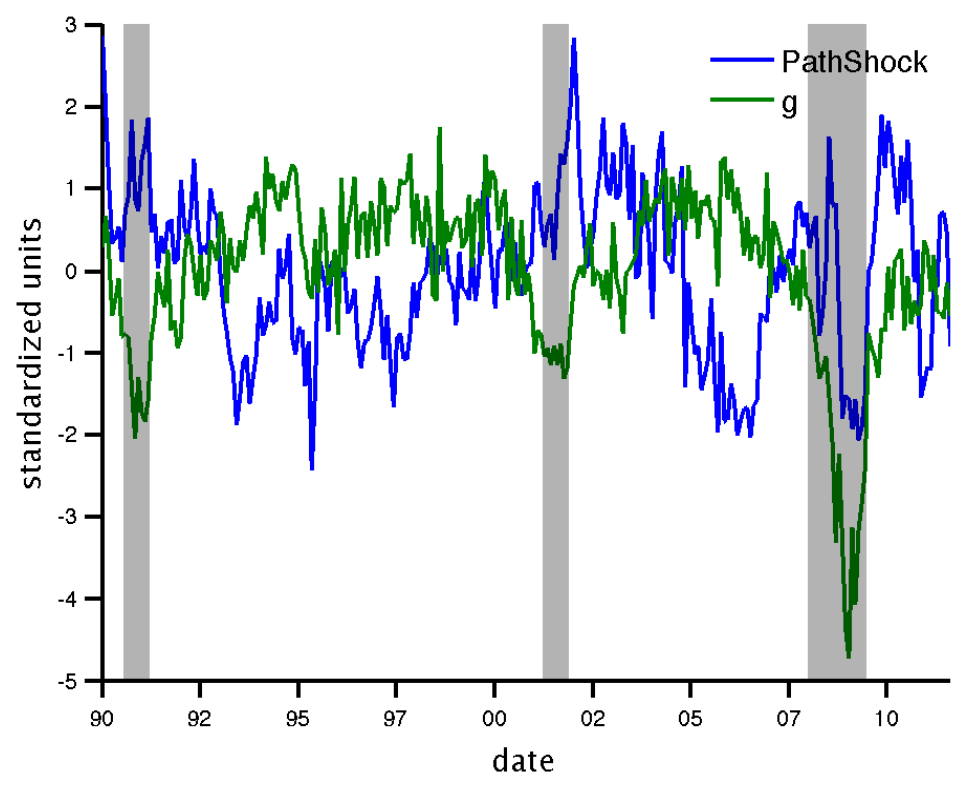

Figure 4. Counter-cyclicality of $\mathcal{P}$ athShock

This figure plots monetary policy path shocks $\mathcal{P}$ athShock (specification 1), and macroeconomic activity, g. Areas shaded in gray indicate NBER recessions. Sample period: 1990:1 - 2011:7. Time series are standardised for easy comparison.

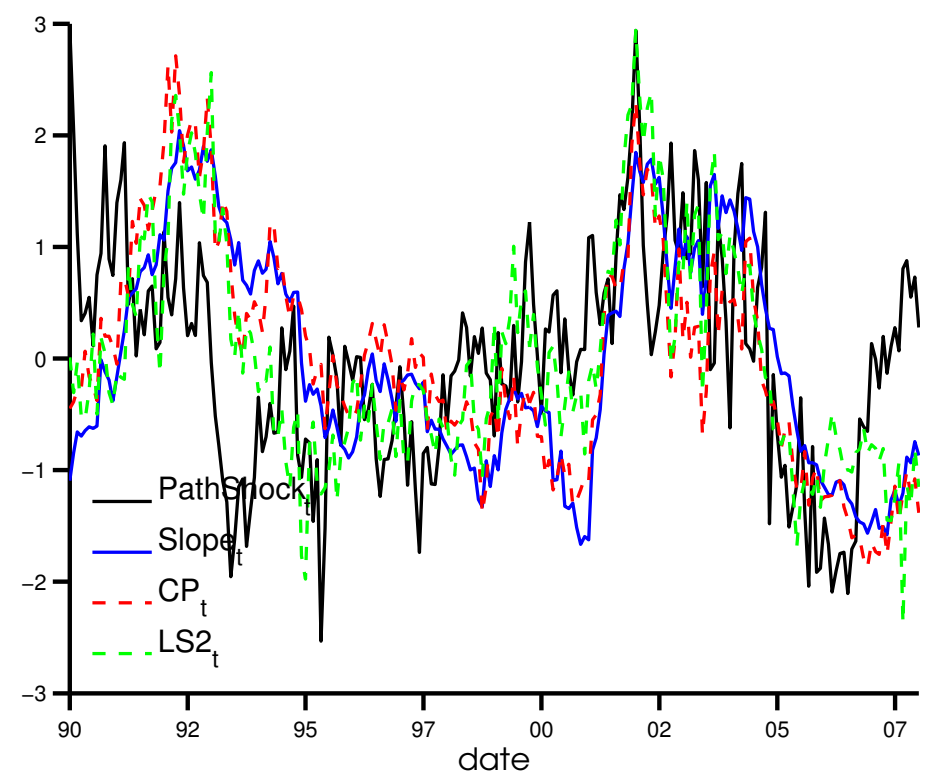

Figure 5. Monetary policy shocks and yield curve information

This figure plots $\mathcal{P}$ athShock against three risk premium proxies: $(i)$ the slope of the yield curve Slope s $_{t}=$ $y_{t}^{(5)}-y_{t}^{(1)} ;(i i)$ the forward rate factor of Cochrane and Piazzesi (2005) $(C P)$; and (iii) a volatility factor from Le and Singleton (2013) (LS2). 

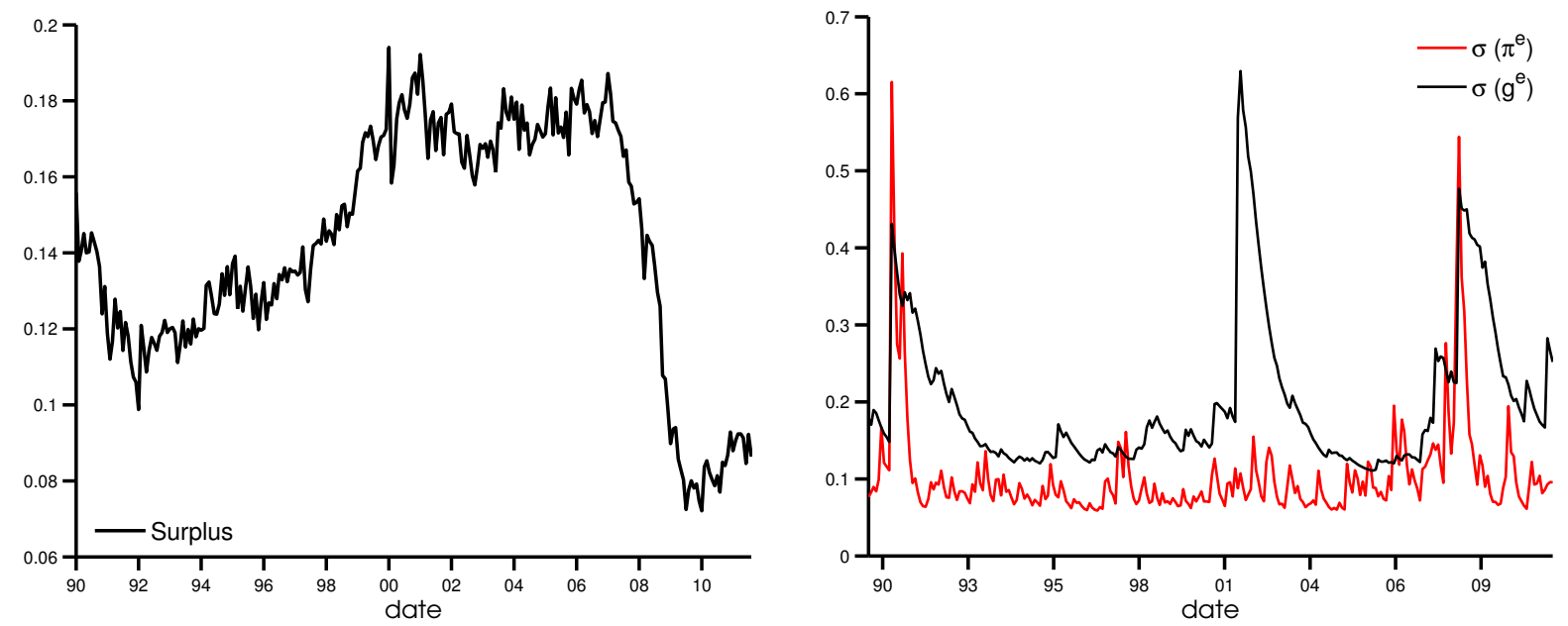

Figure 6. Habit

The left panel of this figure plots a proxy of consumption surplus, $s_{t}$, defined as $s_{t}=\sum_{j=1}^{120} \phi^{j} \Delta c_{t-j}$, where $\phi=0.97^{1 / 3}$ and $\Delta c_{t}$ is the (log) consumption growth between month $t-1$ and $t$. Consumption data consist of seasonally adjusted, real per-capita consumption of nondurables and services.

The right panel plots the conditional volatilities implied by an $\operatorname{ARMA}(1,1)-\operatorname{GARCH}(1,1)$ model fitted to 1-year consensus forecasts of GDP growth $\left(g_{C, t, 1 Y}^{e}\right)$ and inflation $\left(\pi_{C, t, 1 Y}^{e}\right)$. These are proxies for the conditional volatilities of expected GDP and inflation, which we denote $\sigma_{t}\left(g_{C, t, 1 Y}^{e}\right)$ and $\sigma_{t}\left(\pi_{C, t, 1 Y}^{e}\right)$, respectively. 